\title{
RÉGIMEN CONSTITUCIONAL DEL INTERNAMIENTO INVOLUNTARIO Y URGENTE POR TRASTORNO MENTAL
}

\author{
JUAN FRANCISCO SÁNCHEZ BARRILAO
}


SUMARIO

I. INTRODUCCIÓN: PRESENTACIÓN DE LAS SENTENCIAS DEL TRIBUNAL CONSTITUCIONAL 141/2012, 131/2010 y 132/2010. II. MARCO NORMATIVO DEL INTERNAMIENTO DE PERSONAS CON TRASTORNO MENTAL: II.A Marco constitucional; II.B Marco internacional; II.C Marco legal. III. NATURALEZA DEL INTERNAMIENTO DE PERSONAS CON TRASTORNOS MENTALES: III.A Naturaleza del internamiento: entre una medida terapéutica, y una medida de inocuidad y/o asistencial; III.B Naturaleza de la intervención judicial: la autorización judicial en garantía de derechos. IV. EL INTERNAMIENTO INVOLUNTARIO Y URGENTE POR TRASTORNO PSÍQUICO: IV.A Preludio: el internamiento involuntario ordinario por trastorno psíquico; IV.B Presupuestos del internamiento involuntario y urgente por trastorno psíquico; IV.C Garantías en el internamiento involuntario y urgente, y de su ulterior control judicial. V. EL MINISTERIO FISCAL Y EL INTERNAMIENTO INVOLUNTARIO Y URGENTE POR TRASTORNO MENTAL. VI. CONSIDERACIONES FINALES. 


\title{
RÉGIMEN CONSTITUCIONAL DEL INTERNAMIENTO INVOLUNTARIO Y URGENTE POR TRASTORNO MENTAL
}

\author{
JUAN FRANCISCO SÁNCHEZ BARRILAO \\ Prof. Titular Derecho Constitucional \\ Universidad de Granada
}

\section{INTRODUCCIÓN: PRESENTACIÓN DE LAS SENTENCIAS DEL TRIBUNAL CONSTITUCIONAL 141/2012, 131/2010 Y 132/2010}

La reciente Sentencia del Tribunal Constitucional 141/2012, de 2 de julio, junto con las anteriores 131 y 132/2010, ambas de 2 de diciembre, vienen a delimitar, en gran medida, la jurisprudencia constitucional del internamiento involuntario y urgente por trastorno mental (sin perjuicio de otros previos pronunciamientos constitucionales, como son las SSTC 112/1988, de 8 de junio, 104/1990, de 4 de junio, 24/1993, de 21 de enero, y especialmente la 129/1999, de 1 de julio). Es al hilo de dichas Sentencias que revisitemos la cuestión del internamiento involuntario y urgente de personas con trastornos mentales $^{1}$, y a tales efectos que nos propongamos analizar: su marco normativo, distinguiendo entre el estrictamente constitucional, el internacional y el meramente legal; la naturaleza del internamiento con ocasión de trastornos psíquicos, y ello en relación al internamiento como tal, como respecto al tipo de inter-

1 Juan Francisco SÁNCHEZ BARRILAO, «Restricciones en orden a la protección de la salud: restricciones de la libertad por causa de enfermedad infecto-contagiosa e internamientos en establecimientos psiquiátricos», en AA.VV. El principio constitucional de intervención indiciaria, Ricardo Martín Morales (coord.), Grupo Editorial Universitario, Granada, 2000, pp. 133 y ss. 
vención judicial a llevarse a cabo; y de manera concreta, luego, el régimen constitucional del internamiento involuntario y urgente, con especial referencia a sus garantías. Ya, para finalizar, terminaremos con unas consideraciones al respecto del papel del Ministerio Fiscal en tales internamientos, así como a otras cuestiones abiertas por la referida jurisprudencia constitucional en relación al vigente marco jurídico del internamiento involuntario y urgente.

Pero antes de desarrollar el iter recién planteado, quisiéramos presentar las referidas Sentencias 141/2012, y 131 y 132/2010, por cuanto que (según se ha avanzado) conforman hoy la base jurisprudencial del Tribunal Constitucional más directamente atinente al internamiento involuntario y urgente por trastorno mental, y en cuanto que supuesto de limitación de la libertad personal. Y en este sentido, que comencemos por las Sentencias 131 y 132/2010, resolviendo ambas dos cuestiones de inconstitucionalidad planteadas paralela y conjuntamente (cuestiones núms. 4511-1999 y 4542-2001) contra los artículos 211, párrafo primero, del Código civil (y la disp. final 23a LO 1/1996, de 15 de enero, de protección jurídica del menor), y 763.1, párrafos primero y segundo, de la Ley 1/2000, de 7 de enero, de Enjuiciamiento Civil, respectivamente; y en las que, finalmente, se declararía la inconstitucionalidad de dichos preceptos por infracción de los artículos 17.1 y 81.1 de la Constitución, mas no su nulidad (conforme se comentará más adelante) ${ }^{2}$.

En cuanto a la Sentencia del Tribunal Constitucional 141/2012, ahora, ésta viene a resolver un recurso de amparo (el núm. 5070-2009) contra un Auto del Juzgado de Primera Instancia número 16 de Granada, de 21 de mayo de 2007, que ratificó una medida de internamiento involuntario urgente por trastorno psíquico (y contra un ulterior Auto de la Sec. Quinta de la Audiencia Provincial de Granada, de 1 de abril de 2009, que desestimó el recurso de apelación interpuesto contra el anterior), concediéndolo; y ello, por vulneración del derecho fundamental a la libertad personal del recurrente (art. 17.1 CE), en base a: un incumplimiento del plazo de 72 horas que el juez tenía para resolver sobre la ratificación de la medida de internamiento (pues tardó 14 días!); la dejación por parte del juez del deber de dar la necesaria

2 Sobre ambas SSTC, por ejemplo: M. ${ }^{a}$ Fernanda MORETÓN SANZ, «Dos nuevos pronunciamientos del TC sobre el internamiento forzoso en establecimiento de salud mental como medida privativa de libertad: cuestiones sobre ingresos no voluntarios en centros geriátricos», Revista de Derecho UNED, núm. 7, 2010; y Óscar Daniel LUDEÑA BENÍTEZ, «Aspectos constitucionales y procesales del internamiento por razón de trastorno psíquico: especial referencia a la STC 132/10 y a la naturaleza jurídica-procesal de la institución», Noticias Jurídicas, Octubre 2011, en http://noticias. juridicas.com/articulos/45-Derecho\%20Civil/201110-465213845624874.html $(10 / 08 / 2012)$. 
información al internado «sobre sus derechos dentro del procedimiento», «a designar abogado y procurador para su defensa», y «sobre la práctica de posibles pruebas pertinentes»; y por carecer el referido Auto de «la motivación reforzada que le era exigible», dado que relativo a una medida privativa de libertad (FJ núm. 7). Sin perjuicio de profundizar luego en la argumentación del Constitucional sobre tales vulneraciones, sí resulta interesante subrayar, y al comienzo de este trabajo, cómo el Tribunal (al menos, su Sala Segunda) pretende ofrecer una aproximación genérica y abstracta del régimen constitucional del internamiento involuntario y urgente por trastorno mental, más allá del concreto caso objeto del amparo; no en vano, el propio recurrente llegó a renunciar a la demanda de amparo (AH núm. 11), si bien el Tribunal decidió resolver sobre el fondo del asunto ante la «innegable importancia social» del mismo, al afectar la cuestión suscitada a un colectivo de persona «especialmente vulnerable» (FJ núm. 2) $)^{3}$.

3 Por su importancia, permítasenos recoger el contenido del FJ núm. 2 completo: «El examen del fondo del recurso, tal como queda así delimitado, no ha de quedar interferido porque el demandante, ya terminada la tramitación del proceso de amparo, haya presentado un escrito pidiendo el archivo del recurso por la pérdida de interés legítimo. / Dicha solicitud de desistimiento ha de ser rechazada con base en la doctrina de este Tribunal que atempera el carácter rogado atribuido a esta Jurisdicción constitucional, cuando "razones de interés público, vinculadas a la dimensión objetiva de los derechos fundamentales" determinan la necesidad de hacer un pronunciamiento expreso sobre el fondo del asunto pese al abandono de la respectiva pretensión de parte (STC 51/1998, de 3 de marzo, FJ 2; AATC 265/2002, de 9 de diciembre, FJ Único; 330/2003, de 20 de octubre, FFJJ 1 y 2). / En este caso, la concurrencia de ese interés público se deriva, ante todo, del hecho de que se trata del primer recurso de amparo en el que se enjuicia desde la óptica del derecho fundamental a la libertad personal, un caso de internamiento psiquiátrico urgente, con las peculiaridades que éste presenta en nuestro ordenamiento al acordarse ab initio sin control judicial, conforme luego veremos. Y en segundo lugar y en línea con lo defendido por el Ministerio Fiscal en el escrito de alegaciones por el que se opuso a dicho desistimiento, en razón a que el colectivo al que afecta esta medida es con alguna frecuencia el de las personas con discapacidad mental, al cual califica con razón de "especialmente vulnerable", lo que confiere a esta materia una innegable importancia social. Por todo ello corresponde denegar el desistimiento solicitado y entrar al examen de fondo del recurso». Sin duda, con este amparo estamos ante un claro ejemplo de la objetivización que del recurso amparo se ha potenciado con ocasión de la LO 6/2007, de 24 de mayo, por la que se modifica la LO 2/1979, de 3 de octubre, del Tribunal Constitucional, y en especial sus arts. 49.1 y 50.1.b, relativos a la «especial trascendencia» del amparo (y más allá, así, de la mera lesión del derecho fundamental, desde su consideración subjetiva); al respecto de esta reforma, con carácter general, cfr. la STC 155/2009, de 25 de junio (FJ núm. 2). Por otra parte, y en relación a la STC 141/2012, vid. Luis Fernando BARRIOS FLORES, «El ingreso psiquiátrico involuntario de carácter urgente: una revisión, tras la STC 141/2012, de 2 de julio», Revista de la Asociación Española de Neuropsiquiatría, núm. 32 (116), 2012, pp. 829-847. 


\section{MARCO NORMATIVO DEL INTERNAMIENTO DE PERSONAS CON TRASTORNO MENTAL}

\section{II.A Marco constitucional}

A la luz de la jurisprudencia constitucional más arriba referida, el marco normativo-constitucional básico del internamiento involuntario y urgente por trastorno mental viene determinado por el derecho fundamental a la libertad personal (art. 17.1 CE), así como por las garantías directamente determinadas en relación a su limitación ${ }^{4} ;$ y ello, en tanto que este derecho no sólo se proyecta ante intervenciones públicas de carácter punitivo, sino ante cualquier tipo de limitación de la libertad física. Ahora bien, el que la libertad personal o física sea el derecho que más directamente se ha relacionado con el internamiento involuntario de personas con trastornos mentales, no significa que lo agote; así, se ha de partir de cómo el trastorno mental supone una psicopatología ${ }^{5}$, y consecuentemente que, entonces, quepa abrir el marco constitucional del internamiento más allá de la referida libertad personal. En este sentido estaría: de un lado, y asimismo como derecho fundamental, el derecho a la «integridad física y moral» de toda persona, y la proscripción de «tratos inhumanos o degradantes» (art. $15 \mathrm{CE})^{6}$; y de otro, y como

4 Entre otros, Teresa FREIXES SANJUÁN y José Carlos REMOTTI CARBONELL, El derecho a la libertad personal: análisis de constitución, legislación, tratados internacionales y jurisprudencia (Tribunal Europeo y Tribunal Constitucional), Promociones y Publicaciones Universitarias, Barcelona, 1993; Joaquín GARCÍA MORILLO, El derecho a la libertad personal: (detención, privación y restricción de libertad), Universitat de València, Valencia, 1995; Julio BANACLOCHE PALAO, La libertad personal y sus limitaciones: detenciones y retenciones en el derecho español, McGraw-Hill Interamericana de España, Madrid, 1996; Francisco FERNÁNDEZ SEGADO, «El derecho a la libertad y seguridad personal. Su construcción jurisprudencial», Asamblea: Revista Parlamentaria de la Asamblea de Madrid, núm. 4, 2000, pp. 53 y ss.; y M. ${ }^{a}$ Elena REBATO PEÑO, La detención desde la Constitución, Centro de Estudios Políticos y Constitucionales, Madrid, 2006.

5 Sin perjuicio de que quepa manifestaciones psiquiátricas (alteraciones sobre el sistema nervioso central) al margen de una psicopatología como tal; sería el caso, por ejemplo, de un supuesto esporádico de ingesta de psicotrópicos. Por otra parte, téngase en cuenta la dificultad de definir la enfermedad mental, o psicopatología; a estos efectos, téngase en cuenta las clasificaciones más importantes al respecto: la CIE-10, de la Organización Mundial de la Salud; y el DSM-IV-TR, de la Asociación Psiquiátrica Americana.

6 Por ejemplo: Enrique RUIZ VADILLO, «El Derecho a la vida y a la integridad física», en AA.VV. Los derechos fundamentales y libertades públicas: XII Jornadas de Estudio (I), Dirección General del Servicio Jurídico del Estado (Ministerio de Justicia), Madrid, 1992, pp. 19 y ss.; Epifanio LUPIÓN CRUZ, La salud y su protección en el marco de los derechos fundamentales reconocidos en la Constitución de 1978: el derecho a la integridad física y moral del artículo 15 como derecho a la salud, Universidad de Sevilla, Sevilla, 1992; Francisco Javier DÍAZ REVORIO, «La jurisprudencia del Tribunal Constitucional sobre el derecho a la vida y a la integridad física y moral», Revista Jurídica de Castilla-La Mancha, núm. 17, 1993 , pp. 367 y ss.; y Raúl CANOSA USERA, El derecho a la integridad personal, Lex Nova, Valladolid, 2006. 
meros principios rectores de la política social y económica ahora, el derecho a la salud (art. $43.1 \mathrm{CE})^{7}$, junto al deber de los poderes públicos de realizar políticas de «previsión, tratamiento, rehabilitación e integración» de los disminuidos psíquicos, «a los que prestarán la atención especializada que requieran» $(\text { art. } 49 \mathrm{CE})^{8}$.

Por otra parte, y todavía desde una perspectiva esencialmente sustantiva del régimen constitucional relativo al internamiento de personas con trastornos mentales, se ha tener también en cuenta: de una parte, el reconocimiento de la dignidad de la persona y el «libre desarrollo de la personalidad» (art. 10.1 $\mathrm{CE}$ ), en tanto que fundamento de los derechos fundamentales, pero además como reconocimiento sustantivo de contenidos propios a favor de la persona frente a terceros 9 ; y de otra, la integración de la Declaración Universal de Derechos Humanos y de los demás Tratados y acuerdos internacionales sobre derechos humanos ratificados por España como criterio interpretativo de los

7 Además del anterior trabajo de Epifanio LUPIÓN CRUZ, vid. Manuel JIMÉNEZ DE PARGA I CABRERA, «El derecho a la salud en la Constitución española», en AA.VV. IX Congreso Nacional de Derecho Sanitario, Fundación MAPFRE Medicina, 2003, Madrid, pp. 1 y ss.; y Juan María PEMÁN GAVÍN, «El derecho constitucional a la protección de la salud: una aproximación de conjunto a la vista de la experiencia de tres décadas de vigencia de la Constitución», Revista Aragonesa de Administración Pública, núm. 34, 2009, pp. 11 y ss.

8 De interés, María del Carmen MARTÍNEZ, «Personas con discapacidad intelectual: igualdad jurídica, protección asistencial y asistencia sanitaria», Revista de Ciencias Jurídicas y Sociales, núms. 11-12, 2010, pp. 293 y ss.

9 En torno a la dignidad de la persona y el libre desarrollo de la personalidad: Rafael F. de Asís ROIG, «La apertura constitucional: la dignidad de la persona y el libre desarrollo de la personalidad como fundamentos del orden político y de la paz social», en AA.VV. Comentario a la Constitución socio-económica de España, Cristóbal Molina Navarrete, José Luis Monereo Pérez y María Nieves Moreno Vida (coord.), Comares, Granada, 2002, pp. 153 y ss.; Ignacio GUTIÉRREZ GUTIÉRREZ, Dignidad de la persona y derechos fundamentales, Marcial Pons, Madrid, 2005 (y más recientemente, «Dignidad de la persona y funciones del Derecho constitucional», Estudios de Deusto: Revista de la Universidad de Deusto, vol. 59, núm. 1, 2011, pp. 357 y ss.); Miguel Ángel ALEGRE MARTÍNEZ y Óscar MAGO BENDAHÁN, «Reconocimiento constitucional de la dignidad, individualidad y derechos de la personalidad», Revista de Derecho Político, núm. 66, 2006, pp. 181 y ss.; y Alberto OEHLING DE LOS REYES, «El concepto constitucional de dignidad de la persona: forma de comprensión y modelos predominantes de recepción en la Europa continental», Revista Española de Derecho Constitucional, núm. 91, 2011, pp. 135 y ss. Por cierto, clara manifestación del conflicto entre trastorno mental y la dignidad de la persona y el libre desarrollo de la personalidad ha sido, por tiempo, la consideración de la homosexualidad como enfermedad mental; o también, las condiciones de internamiento y tratamientos recibidos por los enfermos mentales en el pasado. 
derechos fundamentales y las libertades públicas que la Constitución reconoce $\left(\right.$ art. 10.2 CE) ${ }^{10}$.

Por último, y desde una vertiente procedimental (o formal, ahora) del régimen constitucional relativo al internamiento de personas con trastornos mentales, estarían las diversas garantías previstas constitucionalmente en relación al anterior marco sustantivo: así, y como garantías normativas, las relativas a la supremacía constitucional y la reforma constitucional (arts. 9.1, 53.1, 161.1, 163 y $168 \mathrm{CE})$, y las reservas de ley ordinaria y orgánica (respectivamente, art. 53.1 y $81.1 \mathrm{CE}$ ); como garantías judiciales (y al margen de las específicamente previstas por el art. $17 \mathrm{CE}$ ), la tutela judicial efectiva y las garantías procesales (art. $24 \mathrm{CE}$ ), el amparo ordinario y constitucional (arts. 53.2 y 161.1 CE), y la regulación del Poder Judicial (Tít. VI CE, y en especial art. 117); y como garantías institucionales, la previsión del Defensor del Pueblo (arts. 54 y 162 CE) y del Ministerio Fiscal (arts. 124.1 y $162 \mathrm{CE})$.

\section{II.B Marco internacional}

Advertido más arriba como los tratados internacionales relativos a derechos humanos se articulan constitucionalmente como criterio interpretativo de los derechos fundamentales y las libertades públicas que la Constitución reconoce (nuevamente, art. 10.2 CE) ${ }^{11}$, y promoviendo así un entendimiento constitucional común en materia de derechos fundamentales (siguiendo las tesis de Peter HÄBERLE) ${ }^{12}$, se ha de recordar también la integración directa de dichos tratados en nuestro ordenamiento jurídico (arts. 94.1.c y 96 CE), y ello, en relación a su vinculación a los poderes públicos y a su garantía por los tribunales españoles; pero también, la conformación al tiempo de un sistema multinivel

10 Entre otros, Julio D. GONZÁLEZ CAMPOS, «Las normas internacionales sobre derechos humanos y los derechos fundamentales y libertades reconocidos en la Constitución Española (artículo 10.2 CE)», junto a Pedro CRUZ VILLALÓN y Miguel RODRÍGUEZ-PIÑERO Y BRAVO FERRER, en Tres lecciones sobre la Constitución, Mergablum, Sevilla, 1998. Asimismo, la propia STC 141/2012 (FJ núm. 3).

11 Además de en relación a otros instrumentos internacionales relativos a dichos Tratados, en particular aquellos que están orientados a su propia interpretación y desarrollo; así, precisamente, la referida STC 141/2012 (FJ núm. 3).

12 Peter HÄBERLE, en su ya clásico «Derecho constitucional común europeo», Emilio Mikunda Franco (trad.), Revista de Estudios Políticos, núm. 79, 1993, pp. 7 y ss. 
de garantía de los derechos ${ }^{13}$, e incluso de un marco metaconstitucional de los derechos ${ }^{14}$.

En tal sentido, y a nivel de Naciones Unidas, la Declaración Universal de los Derechos Humanos de 1948 hace referencia a la dignidad (art. 1), la libertad (art. 3), la prohibición de tratos inhumanos y degradantes (art. 5), el reconocimiento de la personalidad (art. 6), el derecho a un recurso efectivo ante los tribunales y en amparo contra actos que violen los derechos fundamentales (art. 8), la prohibición de las detenciones arbitrarias (art. 9), y el derecho de audiencia ante un tribunal para la determinación de los derechos (art. 10). Y con mayor concreción ahora, de un lado, el Pacto Internacional de Derechos Civiles y Políticos, de 1966, con: el genérico derecho a un recurso por violación de derechos fundamentales, nuevamente (art. 2.3), así como la prohibición de tratos inhumanos y degradantes (art. 7); la libertad personal, y especificando la proscripción de las detenciones arbitrarias (art. 9.1 $)^{15}$, el derecho de los detenidos a ser informados de las razones de su detención (art. 9.2) y a ser puestos a disposición judicial (art. 9.3 y 4), así como a ser tratados «humanamente y con el respeto debido a la dignidad inherente al ser humano» (art. 10.1); el derecho de audiencia y debido proceso ante los tribunales para la determinación de los derechos (art. 14.1); y el reconocimiento a toda persona de su personalidad jurídica (art. 16). Y de otra parte, el Pacto Internacional de Derechos Económicos, Sociales y Culturales, también de 1966, con el derecho a la salud mental (art. 12.1) y a la asistencia médica (art. 12.2).

Ya con carácter específico, está también el Documento de Naciones Unidas sobre la Protección de los Enfermos Mentales y el Mejoramiento de la Atención en Salud Mental de 1991, en el que se encuentran recogidos los siguientes principios: el 11,

13 Entre otros: Francisco BALAGUER CALLEJÓN, «Niveles y técnicas internacionales e internas de realización de los derechos en Europa. Una perspectiva constitucional», Revista de Derecho Constitucional Europeo, núm. 1, 2004, pp. 25 y ss.; y Paola BILANCIA, «Las nuevas fronteras de la protección multinivel de los derechos», asimismo en Revista de Derecho Constitucional Europeo, pero ahora núm. 6, 2006, pp. 255 y ss.

14 Vid. Pedro CRUZ VILLALÓN, La Constitución inédita: estudios ante la constitucionalización de Europa, Trotta, Madrid, 2004. Y en la órbita de tal concepción, cfr.: Rafael BUSTOS GISBERT, La Constitución red: un estudio sobre la supraestatalidad y Constitución, Instituto Vasco de Administración Pública, Bilbao, 2005; y Luis I. GORDILLO PÉREZ, Constitución y ordenamientos supranacionales, Centro de Estudios Políticos y Constitucionales, Madrid, 2012.

15 Sigue diciendo el art. 9.1: «Nadie podrá ser privado de su libertad, salvo por las causas fijadas por Ley y con arreglo al procedimiento establecido en ésta». 
relativo al consentimiento para el tratamiento ${ }^{16}$; el 15 , sobre la admisión en general ${ }^{17}$, y el 16, sobre la forzosa ${ }^{18}$; el 17 , en relación al órgano de control y su actuación ${ }^{19}$;

16 «No se empleará restricción física o reclusión involuntaria de un paciente salvo que esto se haga de acuerdo con los procedimientos oficialmente aprobados del establecimiento psiquiátrico y solamente cuando sea el único medio disponible para prevenir daños inmediatos o inminentes al paciente o a terceros. No se prolongará más allá del período, estrictamente necesario para esta finalidad. Todas las instancias de restricción física o reclusión involuntaria, sus motivos y su naturaleza y duración deben ser registrados en la historia clínica del paciente. Un paciente que está físicamente restringido o recluido deberá mantenerse en condiciones humanas y con el cuidado y una supervisión regular y rigurosa provista por miembros calificados del personal. Un representante personal, si lo hay y si es relevante, deberá recibir una rápida notificación sobre cualquier restricción o reclusión compulsiva a la que fuera sometido el paciente».

17 «1. Cuando una persona precisa tratamiento en una institución psiquiátrica se deberán hacer todos los esfuerzos posibles para evitar una admisión forzosa. / 2. El acceso a una institución psiquiátrica debe ser administrado de la misma manera que un acceso a cualquier otro establecimiento por cualquier otra enfermedad. / 3. Todo paciente que no haya sido admitido involuntariamente tendrá derecho a abandonar el establecimiento en cualquier momento, siempre que no se le apliquen los criterios sobre su retención como paciente involuntario, expuestos en el Principio 16; el paciente debe ser informado de ese derecho».

18 «1. Una persona puede ser admitida en una institución psiquiátrica como paciente involuntaria o, habiendo sido admitido voluntariamente como paciente, puede ser retenido involuntariamente en dicha institución si, y sólo si, un profesional de salud mental calificado y autorizado legalmente a este fin, determina, de acuerdo con el Principio 4 mencionado que la persona padece una enfermedad mental y considera: a. Que, debido a la enfermedad mental, hay una seria probabilidad de daño inmediato o inminente para esa persona o para terceros. / b. Que en el caso de que una persona cuya enfermedad mental es grave y cuyo juicio está afectado, la no internación o retención de esa persona puede conducir con mucha probabilidad a un grave deterioro de su estado o impedir darle tratamiento apropiado que sólo puede aplicársele internándola en una institución psiquiátrica mental de acuerdo con el principio de la alternativa menos restrictiva».

$19 \ll 1$. El órgano de control debe ser un órgano judicial u otro órgano independiente e imparcial, instituido por la legislación y funcionando de acuerdo con procedimientos establecidos por dicha legislación. Al formular sus decisiones, ese órgano recibirá la cooperación de uno o más profesionales de salud mental independientes y cualificados y tomará en cuenta sus consejos. / 2. El órgano de control hará la revisión inicial, de la decisión de admitir o retener a una persona como paciente involuntario tan pronto como sea posible después de haber sido adoptada la decisión y la llevará a cabo conforme a procedimientos sencillos y expeditivos como lo especifica la legislación nacional. / 3. El órgano de control revisará periódicamente los casos de pacientes involuntarios a intervalos razonables como lo especifica la legislación nacional. / 4. Un paciente involuntario puede solicitar al órgano de control que le den de alta o lo pasen al estado de paciente voluntario, a intervalos razonables como lo especifica la legislación nacional. / 5. En cada revisión, el órgano de control considerará si los criterios de admisión forzosa expuestos siguen cumpliéndose y si no, el paciente será dado de alta como paciente involuntario. / 6. Si en cualquier momento el profesional de la salud mental, responsable del caso reconoce que las condiciones para la retención de una persona como paciente involuntario ya no se cumplen, el profesional dará la orden de que se le dé de alta como paciente involuntario. /7. Un paciente o su representante personal o cualquier persona interesada, tendrá derecho a apelar ante una instancia más alta de la decisión de admitir al paciente o retenerlo». 
y el 18, acerca de las garantías de los procedimientos ${ }^{20}$. Y al tiempo, la Convención Internacional sobre los Derechos de las Personas con Discapacidad de 2006, en la que, con el propósito de "promover, proteger y asegurar el goce pleno y en condiciones de igualdad de todos los derechos humanos y libertades fundamentales por todas las personas con discapacidad, y promover el respeto de su dignidad inherente» (art. 1), establece: como principio general (entre otros), «[e]l respeto de la dignidad inherente, la autonomía individual, incluida la libertad de tomar las propias decisiones, y la independencia de las personas» (art. 3.a); el reconocimiento de la libertad personal de las personas con discapacidad, y en igualdad de condiciones con las demás, de manera que «[n]o se vean privadas de su libertad ilegal o arbitrariamente y que cualquier privación de libertad sea de conformidad con la ley, y que la existencia de una discapacidad no justifique en ningún caso una privación de la libertad» (art. 14.1.b) ${ }^{21}$; la

20 «1. El paciente tendrá el derecho a elegir y designar a un asesor legal que lo represente en calidad de paciente, incluso para que lo represente en cualquier queja o apelación. Si el paciente no puede conseguir esos servicios, se le designará un asesor sin que el paciente deba pagar, en la medida en que carezca de los medios suficientes para hacerlo. / 2. El paciente tendrá también derecho, si es necesario, a los servicios de un intérprete. Cuando esos servicios sean necesarios y el paciente no pueda hacerse cargo de ellos, se le facilitarán sin que el paciente tenga que retribuirlos, en la medida en que éste carezca de los medios suficientes para pagar. / 3. El paciente y el asesor pueden requerir y presentar ante cualquier audiencia un informe independiente de salud mental y cualesquiera otros informes, ya sea orales o escritos y otras pruebas que sean pertinentes y aceptables. / 4. Se le darán al paciente o al asesor del paciente, copias de los registros y de cualesquiera informes o documentos para ser presentados, con excepción de los casos en los que se determine que revelar al paciente ciertos datos ocasionaría un grave daño a su salud o pondría en peligro la seguridad de otras. /7. En toda decisión sobre si la audiencia o una parte de ella deba ser pública o privada y pueda tener difusión pública, deben merecer plena consideración los propios deseos del paciente, la necesidad de respetar su intimidad y la de otras personas y la necesidad de evitar graves daños a la salud del paciente o evitar que corra peligro la seguridad de terceros. / 8. La decisión que surja de la audiencia y sus motivaciones deben expresarse por escrito. Se entregarán copias al paciente y a su representante personal y al asesor. Al decidir si la decisión será publicada en su totalidad o en parte, se tomarán en cuenta los propios deseos del paciente, la necesidad de respetar su vida privada y la de otras personas, el interés público en la administración abierta de la justicia y la necesidad de prevenir daños graves a la salud del paciente y de evitar poner en riesgo la seguridad de terceros». También destacan los principios núms. 13 (derechos del paciente y condiciones en las instituciones psiquiátricas) y 14 (recursos de las instituciones psiquiátricas).

21 Asimismo, Art. 14.2: «Los Estados Partes asegurarán que las personas con discapacidad que se vean privadas de su libertad en razón de un proceso tengan, en igualdad de condiciones con las demás, derecho a garantías de conformidad con el derecho internacional de los derechos humanos y a ser tratadas de conformidad con los objetivos y principios de la presente Convención, incluida la realización de ajustes razonables». 
obligación de los Estados a adoptar «las medidas de carácter legislativo, administrativo, judicial o de otra índole que sean efectivas para evitar que las personas con discapacidad, en igualdad de condiciones con las demás, sean sometidas a $[\ldots]$ tratos $[\ldots]$ crueles, inhumanos o degradantes» (art. 15.2); el derecho a vivir de forma independiente (art. 19) 22 ; el respeto de la privacidad (art. 22); y el derecho de acceso a la salud (art. 25).

A nivel regional y europeo, por otra parte $^{23}$, en el Convenio para la Protección de los Derechos Humanos y de las Libertades Fundamentales destaca, a los efectos de estas páginas, la prohibición de «tratos inhumanos o degradantes» (art. 3) y el reconocimiento de la libertad personal, de manera que nadie pueda ser privado de la misma «salvo, en los casos siguientes y con arreglo al procedimiento establecido por la Ley» (art. 5.1), especificando así el internamiento, conforme a derecho, de personas susceptibles de "propagar una enfermedad contagiosa, de un enajenado, de un alcohólico, de un toxicómano o de un vagabundo» (art. 5.1.e); además, las personas internadas deberán ser informadas, «en el más breve plazo y en una lengua» que comprendan, de los motivos del internamiento (art. 5.2), y tienen «derecho a presentar un recurso ante un órgano judicial, a fin de que se pronuncie en breve plazo sobre la legalidad de su privación de libertad y ordene su puesta en libertad si fuera ilegal» (art. 5.4 $)^{24}$. A ello se ha de sumar una importante doctrina jurisprudencial, por parte del Tribunal

22 En particular, que las personas «con discapacidad tengan acceso a una variedad de servicios de asistencia domiciliaria, residencial y otros servicios de apoyo de la comunidad, incluida la asistencia personal que sea necesaria para facilitar su existencia y su inclusión en la comunidad y para evitar su aislamiento o separación de ésta» (art. 19.b).

23. Lucía GARCÍA GARCÍA, Marco jurídico de la enfermedad mental: incapacitación e internamiento, Revista General de Derecho, Valencia, 2000, pp. 183 y ss.; Juan José CARRASCO GÓMEZ, «Regulación legal de los internamientos psiquiátricos en España», Revista Latinoamericana de Derecho Médico y Medicina Legal, núms. 7 y 8, 2002-2003, pp. 121 y ss.; y especialmente, Luis Fernando BARRIOS FLORES, «Derechos Humanos y salud mental en Europa», Norte de Salud Mental, vol. VIII, núm. 36, 2010, pp. 55 y ss., trabajo que seguimos en este apartado.

24 «Toda persona víctima de una detención preventiva o de un internamiento en condiciones contrarias a las disposiciones de este artículo tendrá derecho a una reparación» (art. 5.5). Por otra parte se reconoce el derecho de toda persona a que «sea oída equitativa, públicamente y dentro de un plazo razonable, por un Tribunal independiente e imparcial, establecido por la Ley, que decidirá los litigios sobre sus derechos y obligaciones de carácter civil o sobre el fundamento de cualquier acusación en materia penal dirigida contra ella...» (art. 6.1). 
Europeo de Derechos Humanos, en interpretación del alcance de los anteriores preceptos ${ }^{25}$.

En desarrollo del referido artículo 3 del Convenio, está también el Convenio Europeo para la Prevención de la Tortura y de las Penas o Tratos Inhumanos o Degradantes, de $2006^{26}$. Y asimismo, el anterior Convenio Europeo sobre los Derechos Humanos y la Biomedicina de 2003, destacando (a los efectos de este trabajo) sus artículos: 6.1 (las intervenciones que recaigan sobre una persona que no tenga capacidad para expresar su consentimiento únicamente podrá efectuarse cuando redunde en su beneficio) y 6.3 (en caso de disfunción mental, tal intervención sólo cabe con autorización del representante, autoridad o persona o institución señalada por la ley, y debiendo intervenir el afectado, en la medida que sea posible, en el procedimiento de autorización), 7 (únicamente cabe el tratamiento de un trastorno mental sin consentimiento, en caso de riesgo grave para la salud del paciente) y 8 (sobre la procedencia de intervenciones indispensables desde el punto de vista médico a favor del afectado sin consentimiento previo, siempre que éste no pueda obtenerse y concurra una situaciones de urgencia).

Todavía en el ámbito del Consejo de Europa, destacan asimismo diversas Recomendaciones relativas a la salud mental y a la protección de los enfermos mentales, sobresaliendo la Recomendación 10 de 2004, relativa a la protección de los

25 Así, y hasta mediados de 2005: Winterwerp vs. Holanda, de 24 de octubre de 1979; X vs. Reino Unido, de 5 de noviembre de 1981; Luberti vs. Italia, de 23 de febrero de 1984; Ashingdane vs. Reino Unido, de 28 de mayo de 1985; Nielsen vs. Dinamarca, de 28 de noviembre de 1988; Van der Leer vs. Holanda, de 21 de febrero de 1990; E. vs. Noruega, de 29 de agosto de 1990; Wassink vs. Holanda, de 27 de septiembre de 1990; Koendjbiharie vs. Holanda, de 25 de octubre de 1990; Keus vs. Holanda, de 25 de octubre de 1990; Megyeri vs. Alemania, de 12 de mayo de 1992; Herczegfalvy vs. Austria, de 24 de septiembre de 1992; Silva Rocha vs. Portugal, de 15 de noviembre de 1996; Eriksen vs. Noruega, de 27 de mayo de 1997; Johnson vs. Reino Unido, de 24 de octubre de 1997; Aerts vs. Bélgica, de 30 de julio de 1998; Erkalo vs. Holanda, de 2 de septiembre de 1998; Varbanov vs. Bulgaria, de 5 de octubre de 2000; D.N. vs. Suiza, de 29 marzo de 2001; Keenan vs. Reino Unido, de 3 de abril de 2001; Rutten vs. Holanda, de 24 de julio de 2001; Magalbaes Pedreira vs. Portugal, de 26 de febrero de 2002; H.M. vs. Suiza, de 26 de febrero de 2002; Paul E Audrey Edwards vs. Reino Unido, de 14 de marzo de 2002; Lutz vs. Francia, de 26 de marzo de 2002; L.R. vs. Francia, de 27 de junio de 2002; Noubaud et al. vs. Francia, de 9 de julio de 2002; Hutchison Reid vs. Reino Unido, de 20 de febrero de 2003; Herz vs. Alemania, de 12 de junio de 2003; Lutz vs. Francia, de 17 de junio de 2003; Tracik vs. Eslovaquia, de 14 de octubre de 2003; Rakevich vs. Rusia, de 28 de octubre de 2003; Worwa vs. Polonia, de 27 de noviembre de 2003; Morsink vs. Holanda, de 11 de abril de 2004; M.R.L. y M.J.D. vs. Francia, de 19 de mayo de 2004; Tam vs. Eslovaquia, de 22 de junio de 2004; H.L. vs. Reino Unido, de 5 de octubre de 2004; Kolanis vs. Reino Unido, de 21 de junio de 2005; y Storck vs. Alemania, de 16 de junio de 2005.

26 Y en virtud del cual se crea un Comité Europeo para la prevención de la tortura y de las penas o tratos inhumanos o degradantes, el cual elabora informes generales en los que se las «Normas del CPT», destacando en relación a los internamientos por trastornos mentales el octavo Informe [CPT/Inf (98) 12]. 
derechos del hombre y de la dignidad de las personas aquejadas de enfermedades mentales (Comité de Ministros, 896 a reunión, de 22 de septiembre de 2004) ${ }^{27}$, conforme a la cual: se recogen diversos principios $^{28}$; se establecen criterios, análo-

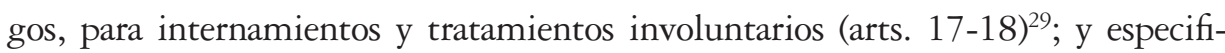
cando además en relación al ingreso involuntario (arts. 20-25) $)^{30}$ y de urgencia ${ }^{31}$.

27 Otras son (hasta 2009): la Rec. 818 (1977), relativa a la situación de los enfermos mentales (Asamblea Parlamentaria, 12. a sesión, de 8 de octubre de 1977); la Rec. N. ${ }^{\circ}$ R (80) 4, respecto del paciente como partícipe activo de su propio tratamiento (Comité de Ministros, 318. ${ }^{a}$ reunión, de 30 de abril de 1980); la Rec. N. ${ }^{\circ} \mathrm{R}$ (83) 2, sobre la protección jurídica de las personas aquejadas por enfermedades mentales e ingresadas como pacientes involuntarios (Comité de Ministros, 356. ${ }^{a}$ reunión, de 22 de febrero de 1983); la Rec. N. ${ }^{\circ} \mathrm{R}$ (87) 3, sobre reglas penitenciarias europeas (Comité de Ministros, 404. reunión, de 12 de febrero de 1987); la Rec. N. ${ }^{\circ} \mathrm{R}$ (91) 15, sobre cooperación europea en materia de estudios epidemiológicos en el ámbito de la salud mental (Comité de Ministros, 463. reunión, de 11 de octubre de 1991); la Rec. 1185 (1992), sobre políticas de rehabilitación de personas discapacitadas (Asamblea Parlamentaria, 6. ${ }^{a}$ sesión, de 7 de mayo de 1992); la Rec. N. ${ }^{\circ}$ R (92) 6, sobre una política coherente en materia de integración de personas con minusvalías (Comité de Ministros, 474 . $^{2}$ reunión, de 9 de abril de 1992); la Rec. 1235 (1994), relativa a la psiquiatría y a los derechos humanos (Asamblea Parlamentaria, 10. sesión, de 12 de abril de 1994); la Rec. N. ${ }^{\circ} \mathrm{R}$ (98) 7, en lo que concierne a los aspectos éticos y organizativos de los cuidados de la salud en el medio penitenciario (Comité de Ministros, 627. a reunión, de 8 de abril de 1998); la Rec. (2006) 2, sobre Reglas Penitenciarias europeas (Comité de Ministros, 952. ${ }^{a}$ reunión, de 11 de enero de 2006); y la Rec (2009) 3, sobre seguimiento de la protección de los derechos del hombre y de la dignidad de las personas aquejadas de trastornos mentales (Comité de Ministros, 1057. a reunión, de 20 de mayo de 2009).

28 Como el de no discriminación (art. 3), conservación del ejercicio de los derechos civiles y políticos del paciente mental (art. 4), restricción mínima (art. 8) y equiparación de las condiciones de vida de los establecimientos psiquiátricos al estándar asistencial general (art. 9).

29 Se ha de estar aquejado de un trastorno mental, y el estado de la persona ha de comportar un riesgo grave para sí o para terceros; no ha de existir medios menos restrictivos a fin de suministrar los cuidados apropiados; y ha de tenerse en cuenta la opinión de la persona afectada. Respecto al tratamiento involuntario, específicamente, éste debe: responder a síntomas específicos; ser proporcional al estado de salud y ostentar un fin terapéutico; ha de administrarse por personal cualificado, sustituirse lo antes posible por un tratamiento voluntario, y ser reevaluado periódicamente (arts. 12, 17.iii).

30 La decisión la ha de adoptar un tribunal o instancia competente, teniendo en cuenta el parecer del paciente y conforme a procedimiento legalmente previsto; se ha de consignar un período máximo de reevaluación, sin perjuicio del derecho del paciente a solicitar la misma y a ejercer los correspondientes recursos; se ha de basar en un dictamen médico; se tiene que informar y consultar también al representante del paciente y a sus allegados; el ingreso ha de finalizar en caso de que dejen de cumplirse los criterios de ingreso; y ha de quedar garantizado el derecho del interno a la información de las razones que motivan el ingreso (así como los criterios para su prolongación y los recursos disponibles), y el de comunicarse con su abogado y su representante.

31 Por breve plazo y, para su prorroga, por decisión de un tribunal u otra instancia competente; y la posibilidad, aun de manera excepcional y por el tiempo mínimo indispensable, un internamiento a fin de evaluar un trastorno mental que suponga un riesgo real de daño grave para su salud o para un tercero (requiriendo, eso sí, específicas condiciones). 
Asimismo, la Carta Social Europea, la cual contiene varios artículos relacionados con la salud mental: el 11, el derecho a la protección de la salud; el 13, el derecho a la asistencia social y médica; y el 15, derecho de las personas mentalmente disminuidas a la readaptación profesional y social ${ }^{32}$.

Y, por último, la Carta de los Derechos Fundamentales de la Unión Europea (Tratado de Lisboa), que dedica genéricos preceptos en relación a la materia que estamos tratando, destacando sus artículos: 1, de la dignidad, como derecho; 3.1, acerca de la integridad psíquica, y especialmente 3.2.a, sobre el consentimiento libre e informado; 26, en relación a la integración de las personas discapacitadas; y 35, respecto a la protección de la salud.

\section{II.C Marco legal}

En cuanto al régimen legal en despliegue del anterior marco constitucional relativo al internamiento de personas con trastornos mentales, está, aun provisionalmente, el artículo 763 de la Ley de Enjuiciamiento Civil, conforme la Ley $1 / 2000$, de 7 de enero ${ }^{33}$, derogando el artículo 211 del Código

32 Además, está la Resolución del Consejo, de 18 de noviembre de 1999, sobre promoción de la salud mental, las Conclusiones del Consejo, de 2 de junio de 2003, sobre la lucha contra la estigmatización y la discriminación en relación con la enfermedad mental, y el «Libro Verde para mejorar la salud mental de la población. Hacia una estrategia de la Unión Europea en materia de salud mental», de 14 de octubre de 2005.

33 Art. 763 LEC: «1. El internamiento, por razón de trastorno psíquico, de una persona que no esté en condiciones de decidirlo por sí, aunque esté sometida a la patria potestad o a tutela, requerirá autorización judicial, que será recabada del tribunal del lugar donde resida la persona afectada por el internamiento. / La autorización será previa a dicho internamiento, salvo que razones de urgencia hicieren necesaria la inmediata adopción de la medida. En este caso, el responsable del centro en que se hubiere producido el internamiento deberá dar cuenta de éste al tribunal competente lo antes posible y, en todo caso, dentro del plazo de veinticuatro horas, a los efectos de que se proceda a la preceptiva ratificación de dicha medida, que deberá efectuarse en el plazo máximo de setenta y dos horas desde que el internamiento llegue a conocimiento del tribunal. / En los casos de internamientos urgentes, la competencia para la ratificación de la medida corresponderá al tribunal del lugar en que radique el centro donde se haya producido el internamiento. Dicho tribunal deberá actuar, en su caso, conforme a lo dispuesto en el apartado 3 del artículo 757 de la presente Ley. / 2. El internamiento de menores se realizará siempre en un establecimiento de salud mental adecuado a su edad, previo informe de los servicios de asistencia al menor. /3. Antes de conceder la autorización o de ratificar el internamiento que ya se ha efectuado, el tribunal oirá a la persona afectada por la decisión, al Ministerio Fiscal y a cualquier otra persona cuya comparecencia estime conveniente o le sea solicitada por el afectado por la medida. Además, y sin perjuicio de que pueda practicar cualquier otra prueba que estime relevante para el caso, el tribunal deberá examinar por si mismo a la persona de cuyo internamiento se trate y oír 
Civil $^{34}$ (en la dicción dada por disp. final duodécima LO 1/1996, de 15 de enero, de Protección Jurídica del Menor, y según disp. derogatoria única, apartado 2, L $1 / 2000)^{35}$, y de acuerdo a las referidas Sentencias del Tribunal Constitucional 131 y 132/2010. Decimos provisionalmente, por cuanto que la Sentencia 132/2010, y en línea con la paralela 131/2010 (y la anterior STC 129/1999, FJ núm. 2), vendría a declarar la «inconstitucionalidad de aquellos incisos de los párrafos primero y segundo del artículo 763.1 [...] que posibilitan la decisión de internamiento no voluntario por razón de trastorno psíquico, pues, en tanto que constitutiva de una privación de libertad, esta medida sólo puede regularse mediante ley orgánica» (FJ núm. 3); mas sin anudar a tal inconstitucionalidad «la declaración de nulidad pues esta última crearía un vacío en el Ordenamiento jurídico no deseable, máxime no habiéndose cuestionado su contenido material» (FJ núm. 3$)^{36}$. Por tanto, una vigencia provisional a la espera de que el legisla-

el dictamen de un facultativo por él designado. En todas las actuaciones, la persona afectada por la medida de internamiento podrá disponer de representación y defensa en los términos señalados en el artículo 758 de la presente Ley. / En todo caso, la decisión que el tribunal adopte en relación con el internamiento será susceptible de recurso de apelación. / 4. En la misma resolución que acuerde el internamiento se expresará la obligación de los facultativos que atiendan a la persona internada de informar periódicamente al tribunal sobre la necesidad de mantener la medida, sin perjuicio de los demás informes que el tribunal pueda requerir cuando lo crea pertinente. / Los informes periódicos serán emitidos cada seis meses, a no ser que el tribunal, atendida la naturaleza del trastorno que motivó el internamiento, señale un plazo inferior. / Recibidos los referidos informes, el tribunal, previa la práctica, en su caso, de las actuaciones que estime imprescindibles, acordará lo procedente sobre la continuación o no del internamiento. / Sin perjuicio de lo dispuesto en los párrafos anteriores, cuando los facultativos que atiendan a la persona internada consideren que no es necesario mantener el internamiento, darán el alta al enfermo, y lo comunicarán inmediatamente al tribunal competente».

34 Decía así el art. 211.1 CC: «El internamiento por razón de trastorno psíquico, de una persona que no esté en condiciones de decidirlo por sí, aunque esté sometida a la patria potestad, requerirá autorización judicial. Esta será previa al internamiento, salvo que razones de urgencia hiciesen necesaria la inmediata adopción de la medida, de la que se dará cuenta cuanto antes al Juez y, en todo caso, dentro del plazo de veinticuatro horas. El internamiento de menores, se realizará en todo caso en un establecimiento de salud mental adecuado a su edad, previo informe de los servicios de asistencia al menor».

35 Sobre el marco legal previo, vid. Juan Manuel FERNÁNDEZ LÓPEZ, «Garantía de los Derechos Fundamentales de la persona en los internamientos psiquiátricos involuntarios», en AA.VV. Los derechos fundamentales y libertades públicas: XII Jornadas de Estudio (I) ... cit., pp. 149 y ss.

36 Al respecto, no estamos del todo de acuerdo con el razonamiento llevado a cabo por el Tribunal en sus SSTC 129/1999, 131/2010 y 132/2010 (en su conjunto y resultado final), por cuanto que, siendo necesaria la ley orgánica (art. $81 \mathrm{CE}$ ), debería haberse declarado la nulidad, si bien, y en relación al art. 211.1 CC, no respecto a él mismo, sino de la disp. final vigésima 
dor orgánico dé oportuna cobertura legal-orgánica (art. $81 \mathrm{CE}$ ) al internamiento involuntario de personas con trastornos mentales (FJ núm. 3, in fine), y de acuerdo, además (y ahora, añadiría), al marco sustantivo delimitado por el Tribunal Constitucional en su Sentencia 141/2012 (según se viene a mostrar en el último epígrafe del trabajo $)^{37}$.

Todavía en el ámbito de la Ley de Enjuiciamiento Civil, su artículo 760.1, relativo a los posibles contenidos de una sentencia de incapacitación ${ }^{38}$, igualmente vendría a dar cobertura legal al internamiento de una persona con trastorno mental, además de incapaz (así, STC 141/2012, FJ núm. 4) ${ }^{39}$.

En desarrollo ahora del referido artículo 43 de la Constitución, está la Ley 14/1986, de 25 de abril, General de Sanidad, cuyo artículo 20, dedicado a la salud mental, establece, sobre la «base de la plena integración de las actuaciones relativas a la salud mental en el sistema sanitario general y de la total equiparación del enfermo mental a las demás personas», los siguientes principios (entre otros): la potenciación de «los recursos asistenciales a nivel ambulatorio y los

tercera LO 1/1996 por cuanto que no reconoce a dicho precepto la naturaleza de ley orgánica (en tal sentido, en principio, la STC 131/2010, FJ núm. 6); y es que, con todo, tal precepto fue aprobado en el seno y trámite de una ley orgánica (recuérdese, la LO 1/1996), y así cabría considerarse que reúne los requisitos formales exigidos constitucionalmente (sin embargo, la STC 131/2010 deriva finalmente la inconstitucionalidad del art. 211.1 CE, mas sin declarar su nulidad, también en FJ núm. 6). Consecuentemente, y en un paso más, la inconstitucionalidad del art. 763 LEC únicamente afectaría entonces a la disp. derogatoria única, apartado 2, L 1/2000 (en lo relativo a la derogación del art. 211.1 CC), pues el art. 763 cabría considerarse como mero desarrollo procesal del todavía vigente art. 211.1 CC (no del resto del art. 211 CC, claro está, que sí cabría entenderse derogado entonces por L 1/2000). Al respecto de tal entendimiento, ya, Juan Francisco SÁNCHEZ BARRILAO: «Restricciones en orden a la protección de la salud... cit., p. 135; y Las funciones no jurisdiccionales de los jueces en garantía de derechos, Civitas, Madrid, 2002, pp. 209-211. Parecer contrario, y expresamente, se encuentra en el Voto Particular del Magistrado don Pablo García Manzano a la STC 129/1999.

37 Y así, sobre la extensión de tal regulación a la coordinación de la actuación sanitaria y judicial, ya Vicente MAGRO SERVET, «Hacia la necesaria Ley Orgánica integral de coordinación sanitario-judicial para la protección de las personas que sufren problemas de salud mental», Diario La Ley, núm. 7702, 2011.

38 «La sentencia que declare la incapacitación determinará la extensión y los límites de ésta, así como el régimen de tutela o guarda a que haya de quedar sometido el incapacitado, y se pronunciará, en su caso, sobre la necesidad de internamiento, sin perjuicio de lo dispuesto en el artículo 763».

$39 \mathrm{Al}$ respecto, Concepción ESPEJEL JORQUERA, «El internamiento no voluntario por razón de trastorno psíquico. Comentario al art. 763 L.E.C.», Psicopatología Clínica, Legal y Forense, vol. 4, 2004, p. 57. 
sistemas de hospitalización parcial y atención a domicilio» (art. 20.1); y la hospitalización en «unidades psiquiátricas de los hospitales generales» (art. 20.2). Y en cuanto a la autodeterminación de la persona en relación a la Salud (art. 10.1 CE), encontramos la Ley 41/2002, de 14 de noviembre, de Autonomía del Paciente, recogiendo el previo consentimiento libre e informado de todo paciente, y sobresaliendo a tales efectos los artículos: 2 , que contiene los principios básicos ${ }^{40} ; 4,5$ y 6 , relativos al derecho de información sanitaria; 8 , sobre el consentimiento informado ${ }^{41}$; 9, acerca de los límites del consentimiento informado ${ }^{42}$ y el consentimiento por representación ${ }^{43}$, destacando sus párrafos segundo (letra b) y quinto en relación,

40 Art. 2.1: «La dignidad de la persona humana, el respeto a la autonomía de su voluntad y a su intimidad orientarán toda la actividad encaminada a obtener, utilizar, archivar, custodiar y transmitir la información y la documentación clínica» (también, art. 7 L 33/2011, de 4 de octubre, General de Salud Pública). Art. 2.2: «Toda actuación en el ámbito de la sanidad requiere, con carácter general, el previo consentimiento de los pacientes o usuarios. El consentimiento, que debe obtenerse después de que el paciente reciba una información adecuada, se hará por escrito en los supuestos previstos en la Ley». Art. 2.3: «El paciente o usuario tiene derecho a decidir libremente, después de recibir la información adecuada, entre las opciones clínicas disponibles». Y art. 2.4: «Todo paciente o usuario tiene derecho a negarse al tratamiento, excepto en los casos determinados en la Ley. Su negativa al tratamiento constará por escrito».

$41 \ll 1$. Toda actuación en el ámbito de la salud de un paciente necesita el consentimiento libre y voluntario del afectado, una vez que, recibida la información prevista en el artículo 4, haya valorado las opciones propias del caso. / 2. El consentimiento será verbal por regla general. Sin embargo, se prestará por escrito en los casos siguientes: intervención quirúrgica, procedimientos diagnósticos y terapéuticos invasores y, en general, aplicación de procedimientos que suponen riesgos o inconvenientes de notoria y previsible repercusión negativa sobre la salud del paciente. / 3. El consentimiento escrito del paciente será necesario para cada una de las actuaciones especificadas en el punto anterior de este artículo, dejando a salvo la posibilidad de incorporar anejos y otros datos de carácter general, y tendrá información suficiente sobre el procedimiento de aplicación y sobre sus riesgos. / 4. Todo paciente o usuario tiene derecho a ser advertido sobre la posibilidad de utilizar los procedimientos de pronóstico, diagnóstico y terapéuticos que se le apliquen en un proyecto docente o de investigación, que en ningún caso podrá comportar riesgo adicional para su salud. / 5. El paciente puede revocar libremente por escrito su consentimiento en cualquier momento».

42 Art. 9.1: «La renuncia del paciente a recibir información está limitada por el interés de la salud del propio paciente, de terceros, de la colectividad y por las exigencias terapéuticas del caso. Cuando el paciente manifieste expresamente su deseo de no ser informado, se respetará su voluntad haciendo constar su renuncia documentalmente, sin perjuicio de la obtención de su consentimiento previo para la intervención».

43 Art. 9.3: «Se otorgará el consentimiento por representación en los siguientes supuestos: / a. Cuando el paciente no sea capaz de tomar decisiones, a criterio del médico responsable de la asistencia, o su estado físico o psíquico no le permita hacerse cargo de su situación. Si el paciente carece de representante legal, el consentimiento lo prestarán las personas vinculadas a él por 
respectivamente, a la realización por los facultativos de intervenciones clínicas indispensables en favor de la salud del paciente y sin necesidad de contar con su consentimiento cuando exista riesgo inmediato grave para la integridad física o psíquica del enfermo y no es posible conseguir su autorización ${ }^{44}$, y a ciertos principios y garantías en el consentimiento por representación ${ }^{45}$; y 10 , sobre las condiciones de la información y el otorgamiento del consentimiento por escrito.

Por último, la Ley 39/2006, de 14 de diciembre, de Promoción de la Autonomía Personal y Atención a las personas en situación de dependencia, si bien reconoce el derecho a dichas personas a «decidir libremente sobre el ingreso en centro residencial» (art. 4.2.g), a renglón seguido hace referencia al «ejercicio pleno de sus derechos jurisdiccionales en el caso de internamientos involuntarios, garantizándose un proceso contradictorio» (art. 4.2.h, ahora); si bien contempla, así, un supuesto de internamiento involuntario, su no especificación supone su remisión analógica al internamiento involuntario por trastorno men-

razones familiares o de hecho. / b. Cuando el paciente esté incapacitado legalmente. / c. Cuando el paciente menor de edad no sea capaz intelectual ni emocionalmente de comprender el alcance de la intervención. En este caso, el consentimiento lo dará el representante legal del menor después de haber escuchado su opinión si tiene doce años cumplidos. Cuando se trate de menores no incapaces ni incapacitados, pero emancipados o con dieciséis años cumplidos, no cabe prestar el consentimiento por representación. Sin embargo, en caso de actuación de grave riesgo, según el criterio del facultativo, los padres serán informados y su opinión será tenida en cuenta para la toma de la decisión correspondiente».

44 Art. 9.2: «Los facultativos podrán llevar a cabo las intervenciones clínicas indispensables en favor de la salud del paciente, sin necesidad de contar con su consentimiento, en los siguientes casos: / a. Cuando existe riesgo para la salud pública a causa de razones sanitarias establecidas por la Ley. En todo caso, una vez adoptadas las medidas pertinentes, de conformidad con lo establecido en la Ley Orgánica 3/1986, se comunicarán a la autoridad judicial en el plazo máximo de 24 horas siempre que dispongan el internamiento obligatorio de personas. / b. Cuando existe riesgo inmediato grave para la integridad física o psíquica del enfermo y no es posible conseguir su autorización, consultando, cuando las circunstancias lo permitan, a sus familiares o a las personas vinculadas de hecho a él».

45 Art. 9.5: «La prestación del consentimiento por representación será adecuada a las circunstancias y proporcionada a las necesidades que haya que atender, siempre en favor del paciente y con respeto a su dignidad personal. El paciente participará en la medida de lo posible en la toma de decisiones a lo largo del proceso sanitario. Si el paciente es una persona con discapacidad, se le ofrecerán las medidas de apoyo pertinentes, incluida la información en formatos adecuados, siguiendo las reglas marcadas por el principio del diseño para todos de manera que resulten accesibles y comprensibles a las personas con discapacidad, para favorecer que pueda prestar por sí su consentimiento» (según L 26/2011, de 1 de agosto, de adaptación normativa a la Convención Internacional sobre los Derechos de las Personas con Discapacidad). 
tal, tal como viene advirtiendo de manera crítica la doctrina ${ }^{46}$. Y al hilo de ello, también, diversas normas autonómicas contemplando expresamente dicho internamiento involuntario mediante autorización judicial, destacando el caso de la Ley andaluza 6/1999, de 7 de julio, de Atención y Protección de las Personas Mayores (art 45.1) $)^{47}$.

\section{NATURALEZA DEL INTERNAMIENTO DE PERSONAS CON TRASTORNOS MENTALES}

\section{III.A Naturaleza del internamiento: entre una medida terapéutica, y una medida de inocuidad $y / 0$ asistencial}

Una cuestión abierta en torno al anterior marco jurídico presentado en relación al internamiento involuntario de una persona con un trastorno mental es la naturaleza misma del internamiento respecto al trastorno y su tratamiento, y en conexión a su vez a los derechos fundamentales afectados por aquél, asî́ como en cuanto a la propia intervención judicial autorizando aquél; y en ello, en tanto que genéricamente calificado dicho internamiento como «medida cautelar civil», en la referida Sentencia 141/2012 (FJ núm. 4, ab initio). En cuanto a lo primero, de considerarse el internamiento como parte o presupuesto del tratamiento (dado que sea necesario para el tratamiento médico a desarrollar), entendemos que el eje normativo básico en torno al cual giraría el internamiento sería el derecho a la integridad física y moral (art. $15 \mathrm{CE}$ ), junto con el respeto a la dignidad y la personalidad (art. 10.1 CE), y su corolario relativo al consentimiento informado del tratamiento médico (art. 8 L 41/2002) ${ }^{48}$; de este modo, un internamiento que es parte o presupuesto de un tratamiento a una psicopatía se nos presenta como una medida terapéutica, requiriendo consecuentemente del consentimiento del enfermo; y para el caso de que éste no pueda consentir adecuadamente, debiendo entonces sustituirse (con carácter general, art. 9 L 41/2002).

46 Entre otros, M. ${ }^{a}$ Fernanda MORETÓN SANZ, «Dos nuevos pronunciamientos del TC sobre el internamiento forzoso en establecimiento de salud mental como medida privativa de libertad: cuestiones sobre ingresos no voluntarios en centros geriátricos...», cit., pp. 474 y ss.

47 Al respecto, Juan Francisco SÁNCHEZ BARRILAO, Las funciones no jurisdiccionales de los jueces en garantía de derechos... cit., pp. 233 y 234.

48 En general, sobre la integridad física y moral (art. 15 CE) y el consentimiento informado, vid. Pedro RODRÍGUEZ LÓPEZ, «Los derechos constitucionales de las pacientes: derecho a la vida y a la integridad física», Derecho y Salud, Vol. 14, núm. 1, 2006, pp. 189 y ss. 
Ahora bien, en cuanto que un internamiento de tal tipo no es efectiva y personalmente consentido, se ha de considerar éste como no voluntario, y por tanto como limitación a su vez de la libertad personal (art. 17 CE); y de ahí, consiguientemente, la concurrencia de los dos ejes constitucionales desde los que articular jurídicamente el internamiento: integridad física y moral, junto a libertad personal.

Cosa distinta acontece cuando el internamiento involuntario de una persona con un trastorno mental no tiene una finalidad estrictamente terapéutica, pues el tratamiento de la psicopatología puede desarrollarse fuera y/o al margen del internamiento (ambulatoriamente, e incluso de manera involuntaria) ${ }^{49}$; claro que en dicho supuesto cabe la posibilidad, con todo, del internamiento involuntario, si bien en base no al estricto tratamiento de la psicopatología (aunque con causa en ella), sino para evitar también determinadas consecuencias adversas del trastorno mental en cuestión, al poder generarse un riesgo para la integridad o vida de quien tiene el trastorno, como en relación a terceros. En este supuesto, el eje normativo en torno al cual giraría el régimen jurídico del internamiento involuntario sería fundamentalmente la libertad personal, pues tal internamiento, más que medida terapéutica, se asemeja a una medida: de inocuidad, de una parte, que busca evitar determinados riesgos adversos mediante la inocuización del sujeto a fin de reducir su capacidad o potencial de generar daños para sí o terceros ${ }^{50}$; o meramente asistencial, de otra, a tenor del estado pasivo en el que puede encontrarse un sujeto con un trastorno mental, de modo que sea incapaz de valerse adecuadamente por sí mismo (con el consiguiente riesgo para él mismo).

Esta segunda modalidad (de inocuización o de asistencia, según el caso) sería, a nuestro entender, el principal y general motivo de los internamientos involuntarios y urgentes de personas con trastornos mentales, de modo que, sin perjuicio de supuestos en que resulte en extremo urgente tratamientos que requieran internamiento a fin de evitar un riesgo cierto (empeoramiento)

49 Desde esta perspectiva, vid. Onésimo GONZÁLEZ ÁLVAREZ, «Tratamiento ambulatorio involuntario de los enfermos mentales. El trasfondo de un prolongado debate», Cuadernos de Psiquiatría Comunitaria, vol. 6, núm. 1, 2006, pp. 39 y ss.

50 Sobre tales restricciones, nuevamente Juan Francisco SÁNCHEZ BARRILAO, «Restricciones en orden a la protección de la salud...», cit., en especial pp. 139 y 140. Por otra parte, téngase en cuenta la posibilidad estricta de medidas de seguridad en internamientos psiquiátricos; al respecto, Pablo GÓMEZ-ESCOLAR MAZUELA, «Algunas cuestiones sobre la medida de seguridad de internamiento psiquiátrico», Estudios de derecho judicial, núm. 127, 2007, pp. 119 y ss.; o José A. RODRÍGUEZ SÁEZ, «El fundamento ético-jurídico de la medida de seguridad de internamiento psiquiátrico», Diario La Ley, núm. 7762, 2011. 
para la salud mental del sujeto (desde esta perspectiva, entonces, art. $9.2 \mathrm{~L}$ $41 / 2002$ ), son los casos de riesgo físico para la propia persona que padece el trastorno, o para tercero, los que justifican constitucionalmente la modalidad procedimental urgente, en la que se procede al internamiento de la persona sin autorización judicial previa, frente a la ordinaria ${ }^{51}$ y al respecto de lo cual, y sin embargo, el Tribunal Constitucional no repara adecuadamente en su Sentencia $141 / 2012^{52}$.

\section{III.B Naturaleza de la intervención judicial: la autorización judicial en garantía de derechos}

En relación a la naturaleza de la intervención judicial ahora, el juez, desde su independencia (art. 117.1 CE), y como recuerda expresamente la Sentencia 141/2012 (FJ núm. 3) 353 se configura constitucionalmente como el único órgano que puede realizar un juicio sobre limitaciones de derechos fundamentales (y en particular de la libertad personal) ante actuaciones públicas y privadas, y en tanto que garante de los mismos ${ }^{54}$; y desde esta perspectiva, asimismo, el

51 Al respecto, cfr.: principio 16, Documento de Naciones Unidas sobre la Protección de los Enfermos Mentales y el Mejoramiento de la Atención en Salud Mental; y a nivel europeo, la Recomendación 10 de 2004, relativa a la protección de los derechos del hombre y de la dignidad de las personas aquejadas de enfermedades mentales (según se ha recogido antes).

52 Por tanto, si de lo que se trata es sustituir el consentimiento de una persona que padece un trastorno mental a fin de internarlo, y en tanto que dicho internamiento tiene una finalidad terapéutica, requeriría, a nuestro entender, autorización judicial previa (salvo por motivos de estricta urgencia sanitaria, y exclusivamente bajo una finalidad terapéutica, conforme arts. 9.2 L 41/2002, nuevamente, y art. 7 Convenio Europeo sobre los Derechos Humanos y la Biomedicina); autorización que precisamente tendría que evaluar no sólo la necesidad del internamiento (en razón al riesgo que para el sujeto o terceros supone el trastorno mental), sino la conveniencia del mismo (aun involuntaria) en cuanto que positiva para el tratamiento del trastorno psíquico. Y ello, sin perjuicio de que: de un lado, la finalidad terapéutica de un internamiento involuntario, y autorizado judicialmente de manera previa y ordinaria, pueda concurrir, a su vez, con otra finalidad garantista ante el riesgo de daño para la persona que padece el trastorno o para tercero; y de otro, un internamiento adoptado de manera urgente y ulteriormente autorizado judicialmente, pueda a su vez ostentar una finalidad terapéutica, en cuyo caso dicho elemento deberá ser tenido en cuenta por el juez en relación al mantenimiento y ulterior control de tal internamiento.

53 «[...] la decisión de internamiento sólo puede ser acordada judicialmente». Asimismo, SSTC 131/2010 (FJ núm. 4), y 132/2012 (FJ núm. 2).

54 De particular interés, vid. STC 215/1994, de 14 de julio (FJ núm. 3); al respecto de la misma, Juan Francisco SÁNCHEZ BARRILAO, «La previa autorización judicial a la esterilización de disminuidos psíquicos graves (Sentencia del Tribunal Constitucional 215/1994, de 14 de julio de 1994)», Revista General de Derecho, núm. 606, 1995, pp. 1785 y ss. 
expreso requerimiento de intervención judicial desde el marco internacional relativo a los internamientos involuntarios por trastorno mental (anteriormente presentado $)^{55}$.

A tales efectos, tanto el artículo 763 de la Ley de Enjuiciamiento Civil, como el 760.1 también de la Ley de Enjuiciamiento Civil, se integran en el Libro IV de la misma, bajo el epígrafe de los «procesos especiales», y así fuera del Libro III de la anterior Ley de Enjuiciamiento Civil (de 3 de febrero de 1881) relativo a la jurisdicción voluntaria y en vigor hasta que no se apruebe una nueva Ley sobre jurisdicción voluntaria (disp. derogatoria única y disp. final $18^{a}$ L 1/2000); con ello, en principio, bastaría para considerar el procedimiento judicial previsto a fin de autorizar el internamiento de personas que padezcan trastornos psíquicos como jurisdiccional conforme al artículo 117.3 de la Constitución, frente a la posibilidad que ésta otorga de atribuir legalmente funciones no jurisdiccionales en garantía de derechos de acuerdo al 117.4, in fine. Pero es en cambio la concreta función judicial que se plantea legalmente, lo que en verdad hace que dicha función sea jurisdiccional o no, al margen de la calificación o denominación que le dé el legislador; y esto, de acuerdo al grado de confrontación y de garantías que se plantean procedimentalmente, y en relación al fin y naturaleza de la intervención judicial, lo que a su vez repercute en el mayor o menor grado de reconocimiento de la tutela judicial efectiva, así como de las garantías procesales constitucionalmente reconocidas (art. $24 \mathrm{CE})^{56}$.

En tal sentido, se ha partir de cómo la propia Ley de Enjuiciamiento Civil plantea, para el caso de intervención judicial ordinaria en relación a los internamientos por trastornos psíquicos, como un supuesto de «autorización» (art. 763.1 LEC), de manera que dicha intervención consiste en la comprobación por un juez (ante la situación de riesgo que tal internamiento conlleva para ciertos derechos fundamentales) del cumplimiento de determinadas condiciones jurídicamente exigibles en relación a una actuación (el internamiento involuntario) inicialmente limitada en tanto que restrictiva de un derecho (y de ahí,

55 Principio 17 Documento de Naciones Unidas sobre la Protección de los Enfermos Mentales y el Mejoramiento de la Atención en Salud Mental; asimismo, Recomendación 10 de 2004, relativa a la protección de los derechos del hombre y de la dignidad de las personas aquejadas de enfermedades mentales.

56 Nuevamente, Juan Francisco SÁNCHEZ BARRILAO, Las funciones no jurisdiccionales de los jueces en garantía de derechos... cit., pp. 89 y ss., y 185 y ss. 
su referida situación potencial de riesgo $)^{57}$. Y respecto a la ratificación judicial del internamiento urgente (o autorización diferida), ahora, asimismo habría de entenderse en el previo sentido, por cuanto que, y a pesar de llevarse a cabo ésta una vez que la medida se ha adoptado facultativamente, ella no se plantea como un recurso ante dicha medida, sino como un instrumento nuevamente de control cautelar e inmediato del cumplimiento de las condiciones que hacen legítimo el internamiento involuntario por trastorno psíquico decidido directamente por un facultativo ante su urgencia ${ }^{58}$.

Por otra parte, y en cuanto a la concreta articulación procedimental de tal intervención judicial, se ha de estar a lo dispuesto en el Capítulo I ( De las disposiciones generales»), Título I («De los procesos sobre capacidad, filiación, matrimonio y menores»), del referido Libro IV de la Ley de Enjuiciamiento Civil; y a su amparo, su tramitación por juicio verbal (art. 753 LEC). De este modo, y a la vista de la posibilidad de que la persona objeto del internamiento se oponga a esta medida y active las garantías procesales que ostenta (conforme se vendrá a mostrar en el siguiente apartado), que cupiera comprender la intervención judicial como jurisdiccional (art. 117.3 CE) $)^{59}$, y consecuentemente en manifestación plena de la tutela judicial efectiva (art. 24.1 CE) ${ }^{60}$. Mas ello, sin perjuicio de que la persona con trastorno mental no se oponga, ni active ninguna garantía, precisamente por el estado mental en el que se encuentra; o incluso que apoye expresamente su internamiento, aunque no posea las condi-

$57 \mathrm{Al}$ respecto de las autorizaciones judiciales en limitación/garantía de derechos fundamentales, cfr. otra vez Juan Francisco SÁNCHEZ BARRILAO, Las funciones no jurisdiccionales de los jueces en garantía de derechos... cit., pp. 164 y 165. De interés, también, la STC 133/1995, de 25 de septiembre (relativa a la autorización judicial de entrada en domicilio), y en la que define dichas autorizaciones como: «un acto de comprobación donde se ponderan las circunstancias concurrentes y los intereses en conflicto, público o privado, para decidir en definitiva si merece el sacrificio de este, con la limitación consiguiente del derecho fundamental (STC 50/1995)» (FJ núm. 4). Por último, asimismo (desde esta perspectiva sobre el alcance de la intervención del juez), vid. Leopoldo ORTEGA-MONASTERIO Y GASTÓN, «Criterios forense para el internamiento voluntario e involuntario (civil) en España», Psicopatología Clínica, Legal y Forense, vol. 4, 2004, pp. 207 y ss.

58 Sobre el carácter no sólo previo, sino cautelar de la intervención judicial en garantía de derechos, nuevamente Juan Francisco SÁNCHEZ BARRILAO, op. cit., pp. 160 y 161. La anterior consideración plantea consecuencias en relación a la autorización/ratificación judicial a posteriori del internamiento involuntario y urgente de personas con trastornos mentales o psíquicos, como más adelante se viene a mostrar; y ello, además, conforme el Tribunal Constitucional ha venido a delimitar su régimen en su STC 141/2012.

59 Sin perjuicio de la especialidad procedimental, y de las limitaciones de su objeto.

60 Desde esta perspectiva, STC 141/2012 (FJ núm. 6), sin perjuicio de volver a esto más adelante. 
ciones volitivas y cognoscitivas requeridas para consentir adecuadamente, y por tanto que el juez tenga, con todo, que autorizar, en su caso, el internamiento (de interés, art. 752.2 LEC). En tales supuestos, faltaría el elemento de oposición y confrontación que determina el proceso y la actividad jurisdiccional, y consecuentemente que resulte dicha intervención judicial más próxima a una función no jurisdiccional en garantía de derechos (art. 117.4, in fine CE, nuevamente) ${ }^{61}$, lo que a su vez repercutirá en el alcance de la tutela judicial efectiva y en las garantías procesales (otra vez, art. $24 \mathrm{CE}$ ).

\section{EL INTERNAMIENTO INVOLUNTARIO Y URGENTE POR TRASTORNO PSÍQUICO}

\section{IV.A Preludio: el internamiento involuntario ordinario por trastorno psíquico}

De acuerdo al referido artículo 763 de la Ley de Enjuiciamiento Civil, y con carácter ordinario ${ }^{62}$, el internamiento por razón de trastorno psíquico, de una persona que no esté en condiciones de decidirlo por sí (y aunque esté sometida a la patria potestad o a tutela), requiere de autorización judicial previa $(\text { art. 763.1 })^{63}$. Por tanto, se trata de un internamiento de una persona motivado por padecer un trastorno psíquico (mental) ${ }^{64}$, y consecuentemente, a fin de responder a su tratamiento; y a la par, respecto de alguien que no se encuentra en condiciones volitivas y cognitivas suficientes como para consentir oportuna y

${ }^{61} \mathrm{Al}$ respecto, particularmente interesante es la polémica sobre si cabe legítimamente el internamiento voluntario (consentido), en razón a la limitación de la capacidad volitiva y cognoscitiva que cabe presuponer a una persona con trastorno mental; en tal sentido, vid. Jorge GONZÁLEZ FERNÁNDEZ, «Actuación del Médico Forense», en AA.VV. Jornadas sobre Protección Jurídica en la Incapacidad, Fundación Tutelar de La Rioja, Logroño, 2005, p. 84.

62 Para una clasificación del internamiento, y en particular el ordinario y el urgente, vid., entre otros, Enrique PERCELLAR GIMÉNEZ, «El procedimiento de internamiento por razón de trastorno psíquico», Noticias Jurídicas, Febrero 2000, en http://noticias.juridicas.com/ articulos/65-Derecho\%20Procesal\%20Penal/200002-internamiento.html (10/08/2012).

63 «[...] que será recabada del tribunal del lugar donde resida la persona afectada por el internamiento».

64 A tales efectos, para su diagnosis, vid. DSM-IV-TR, 2000 (Diagnostic Statistical Mental Disorders), en http://www.psychiatry.org/practice/dsm/dsm-iv-tr (10/08/2012). Asimismo, STC 141/2012: «El significado de lo que ha de entenderse por trastorno psíquico, transitorio o permanente, en línea con lo dispuesto en instrumentos internacionales, remite a los conocimientos propios de la ciencia médica; sin que en ningún caso puedan considerarse como expresión de trastorno o enfermedad mental la discrepancia del afectado con los valores sociales, culturales, políticos o religiosos imperantes en la comunidad» (FJ núm. 4.a). 
adecuadamente su internamiento (nuevamente, también, art. 8 L 41/2002) ${ }^{65}$. A tales efectos, es que se requiera la autorización judicial previa del juez, sustituyendo así el consentimiento de la persona que padece el trastorno mental (no siendo suficiente el del titular de su patria potestad o tutoría), y en garantía de que tal internamiento sea en beneficio e interés de éste, a la par que dicha medida no restrinja sus derechos fundamentales, en especial su libertad (art. 17.1 $\mathrm{CE}$ ), más allá de lo estrictamente necesario en razón a la finalidad esencialmente terapéutica de la misma ${ }^{66}$.

Al respecto, el Tribunal Constitucional viene estimando (SSTC 112/1988, de 8 de junio —FJ núm. 3-, y 19/1994 -FJ núm. 3-, y siguiendo las SSTEDH de 24 de octubre de 1979, caso Winterwerp, de 5 de noviembre de 1981, caso X contra Reino Unido, y de 23 de febrero de 1984, caso Luberti), como tales internamientos han de cumplir los siguientes requisitos: «a) Haberse probado de manera convincente la enajenación mental del interesado, es decir, haberse demostrado ante la autoridad competente, por medio de un dictamen pericial médico objetivo, la existencia de una perturbación mental real; b) que ésta revista un carácter o amplitud que legitime el internamiento, y c) que los motivos que originariamente justificaron esta decisión pueden dejar de existir, es preciso averiguar si tal perturbación persiste y, en consecuencia, debe continuar el internamiento en interés de la seguridad de los demás ciudadanos, es decir, no puede prolongarse válidamente el internamiento cuando no subsista el trastorno mental que dio origen al mismo» (asimismo, STC 141/2012, FJ núm. 3).

En este sentido, y según se ha avanzado, el juez ha de comprobar el cumplimiento de las condiciones jurídicamente exigibles en relación al internamiento involuntario, dado que inicialmente restringido por cuanto que restrictivo de un derecho fundamental. Y desde tal consideración (y a la luz del juicio de proporcionalidad constitucionalmente requerido en toda medida limitativa

65 Distinguiendo expresamente entre el trastorno mental, y la falta de capacidad de una persona para decidir libre y voluntariamente su internamiento por dicho trastorno (como falta de «capacidad volitiva e intelectiva suficiente para expresar su voluntad y aceptar el ingreso en el centro que se indica»), vid. José Carlos TOMÉ TAMAME, «Autorización judicial de un internamiento no voluntario», Derecho.com, mayo 2004, en http://www.derecho.com/articulos/2004/05/15/autorizaci-n-judicial-de-un-internamiento-no-voluntario/ (10/08/2012). También de interés, vid. Aurora ELOSEGUI SOTOS, «El internamiento forzoso ordinario», en AA.VV. Jornadas sobre Protección Jurídica en la Incapacidad ... cit., p. 77.

66 Decimos esencialmente terapéutica, por cuanto que (y como se ha adelantado) cabe supuestos donde el fin terapéutico concurra con la protección del internado ante un riesgo para sí mismo, o para tercero, con ocasión del trastorno mental. 
de un derecho fundamental o libertad) ${ }^{67}$, verificar: la idoneidad de la medida restrictiva, el internamiento, en tanto que susceptible de conseguir el objetivo propuesto para ella; su necesidad, en el sentido de que no exista otra medida más moderada para la consecución de tal propósito con igual eficacia (por ejemplo, un tratamiento ambulatorio también involuntario $)^{68}$; y la proporcionalidad stricto sensu de la medida, a tenor del carácter equilibrado o ponderado de la intervención en el derecho fundamental, por derivarse de ella más beneficios o ventajas para el propio interno (y el interés general), que perjuicios sobre otros bienes o valores en conflicto.

En relación al diseño de la intervención judicial que plantea el artículo 763.3 de la Ley de Enjuiciamiento Civil, a fin de la referida autorización del internamiento ( $\mathrm{y}$ al margen de que tal medida pueda ser asimismo autorizada judicialmente con ocasión de la declaración judicial de incapacidad, conforme art. 760.1 LEC), el precepto únicamente determina el cumplimiento de concretas garantías, cuales son: audiencia a la persona afectada por la decisión, al Ministerio Fiscal y a cualquier otra persona cuya comparecencia estime conveniente o le sea solicitada por el afectado por la medida; la realización de cualquier prueba que el juez estime relevante para el caso; examen directo del juez sobre la persona de cuyo internamiento se trate; dictamen de un facultativo designado por el juez (dictamen que habrá de atender, según nuestro parecer: al trastorno mental causa del internamiento; a la falta de actitud del sujeto para consentir libre y voluntariamente el internamiento; y al propio internamiento y demás medidas terapéuticas a llevarse a cabo en relación al sujeto) ${ }^{69}$; y el que la persona afectada por la medida de internamiento pueda disponer de representación y defensa en todas las actuaciones, así como la posibilidad de solicitar prueba al respecto (debiéndose entender, como requisito para ello, su previo ofrecimiento, siguiendo la doctrina fijada por la STC 141/2012, FJ núm. 6.a y b, según se

67 Entre otras, y con carácter general, vid. STC 207/1996, de 16 de diciembre (FJ núm. 4.e); y de manera particular, sobre la proporcionalidad del internamiento involuntario (y urgente) por trastorno psíquico, la referida STC 141/2012 (FFJJ núms. 6 y 7), según se vendrá a mostrar más adelante.

68 Precisamente, sobre el tratamiento ambulatorio y obligatorio de trastornos mentales, vid.: Carlos-Eloy FERREIRÓS MARCOS, El tratamiento ambulatorio: cuestiones legales y prácticas, CERMI, Madrid, 2006, en especial pp. 48 y ss. (asimismo, Salud mental y derechos humanos: La cuestión del tratamiento ambulatorio involuntario, CERMI, Madrid, 2007, pp. 224 y ss.); y Fernando SANTANDER CARTAGENA, «Tratamiento ambulatorio involuntario: tal vez sí, pero...», Cuadernos de Psiquiatría Comunitaria, vol. 6, núm. 1, 2006, pp. 47 y ss.

$69 \mathrm{Y}$ para el caso de internamiento de menores, se requiere también informe previo «de los servicios de asistencia al menor»; y además, y como garantía ulterior, el internamiento «se realizará siempre en un establecimiento de salud mental adecuado a su edad» (art. 763.2 LEC). 
viene más adelante a mostrar). Para la concreta articulación procedimental de tal intervención judicial, por otra parte (y según se ha visto), se ha de estar al juicio verbal (art. 753 LEC).

Respecto a la resolución judicial, ésta, entendemos, ha de contener la motivación de la autorización del internamiento en un triple sentido: primero, en relación a la falta de actitud de la persona sujeto de la medida para consentir por sí mismo el internamiento; segundo, respecto al trastorno psíquico que padezca; y tercero, finalmente, sobre la idoneidad de la medida de internamiento, asî como en relación al tratamiento a llevarse a cabo en cuanto al trastorno psíquico diagnosticado. Y esto, naturalmente, en base a las pruebas y dictámenes antes referidos. Por otra parte, la resolución judicial deberá contener también «la obligación de los facultativos que atiendan a la persona internada de informar periódicamente al tribunal sobre la necesidad de mantener la medida», sin perjuicio de otros informes que puedan requerirse ${ }^{70}$, así como los plazos en los que ha emitirse dichos informes, no pudiendo superar éstos los seis meses (art. 763.4 LEC); y a la vista de los mismos, que el juez, previa práctica, incluso (y en su caso), «de las actuaciones que estime imprescindibles», acuerde «lo procedente sobre la continuación o no del internamiento» (art. 763.4 LEC, otra vez).

En todo caso, las anteriores decisiones judiciales que se adopten en relación con un internamiento serán susceptible de recurso de apelación (art. 763.3, in fine, LEC); y ello, sin perjuicio de que «los facultativos que atiendan a la persona internada» puedan considerar en cualquier momento «que no es necesario mantener el internamiento», dando «el alta al enfermo», y comunicándolo «inmediatamente al tribunal competente» (art. 763.4, in fine, LEC).

\section{IV.B Presupuestos del internamiento involuntario y urgente por trastorno psíquico}

No obstante lo anterior, «razones de urgencia» que hagan «necesaria la inmediata adopción de la medida» (el internamiento), ésta podrá ser adoptada por facultativo y sin previa resolución judicial (art 763.1 LEC; además,

70 Informes, entendemos, que igualmente deberán atender a: la continuación del trastorno mental, causa del internamiento (con indicación, en su caso, de posible mejoría o empeoramiento detectado durante el período a evaluar); al mantenimiento de la falta de actitud del sujeto para consentir libre y voluntariamente el internamiento (pues de lo contrario, entiendo, solo éste puede consentir tal internamiento); el propio internamiento y demás medidas terapéuticas llevadas a cabo, y a llevarse a cabo, en relación al sujeto; y por tanto, la necesidad de continuar con el internamiento y demás medidas terapéuticas. 
art. 9.2.b LO 41/2002) ${ }^{71}$; en «este caso, el responsable del centro en que se hubiere producido el internamiento deberá dar cuenta de éste al tribunal competente lo antes posible y, en todo caso, dentro del plazo de veinticuatro horas, a los efectos de que se proceda a la preceptiva ratificación de dicha medida, que deberá efectuarse en el plazo máximo de setenta y dos horas desde que el internamiento llegue a conocimiento del tribunal» (art. 763.1 LEC) ${ }^{72}$. En relación al primero de los plazos indicados, el Tribunal Constitucional en su Sentencia 141/2012 señala: de un lado, que el límite de las 24 horas es legal, resultando constitucionalmente integrado dentro de las 72 horas que determina el artículo 17.2 de la Constitución (FJ núm. 5.c ${ }^{73}$; y de otro, que las 24 horas no es un «plazo fijo sino máximo», de manera que es el máximomáximo que tiene el director del centro para comunicarlo al juez el internamiento, y a contar «desde el momento en que se produce materialmente el ingreso del afectado en el interior del recinto y contra su voluntad» (FJ núm. 5.c $)^{74}$, bajo el apercibimiento de que en caso de exceso podrá tutelarse al interno mediante la garantía del habeas corpus prevista en el artículo 17.4 de la Constitución (FJ núm. 5.c, in fine).

En este caso, además de los presupuestos propios del internamiento ordinario (padecimiento de trastorno psíquico y falta de condiciones volitivas y cognitivas suficientes como para consentir oportuna y adecuadamente su internamiento), la Ley requiere razones de urgencia que hagan necesaria la medida del

71 De interés, Gonzalo ARRUEGO RODRÍGUEZ, «La naturaleza constitucional de la asistencia sanitaria no consentida y los denominados supuestos de "urgencia vital" ", Revista Española de Derecho Constitucional, núm. 82, 2008, en especial pp. 67 y ss.

72 «En los casos de internamientos urgentes, la competencia para la ratificación de la medida corresponderá al tribunal del lugar en que radique el centro donde se haya producido el internamiento. Dicho tribunal deberá actuar, en su caso, conforme a lo dispuesto en el apartado 3 del artículo 757 de la presente Ley» (art. 763.1, in fine, LEC).

73 «Plazo que el legislador actual o futuro no podría elevar en ningún caso más allá de las 72 horas, al resultar vinculante en este ámbito privativo de libertad la limitación que fija el art. 17.2 CE para las detenciones extrajudiciales, el cual, como tenemos declarado, no opera con carácter exclusivo en el orden penal (SSTC 341/1993, de 18 de noviembre, FJ 6; 179/2000, de 26 de junio, FJ 2; 53/2002, de 27 de febrero, FJ 6)».

74 Y sigue diciendo el Tribunal, en relación a supuestos de internamientos originariamente voluntarios, pero transformados en involuntarios al tiempo: «Precisión esta última importante, en aquellos casos en los que la persona ha podido acceder inicialmente al tratamiento de manera voluntaria y en algún momento posterior exterioriza su cambio de criterio, siendo en ese preciso momento cuando, tornándose en involuntario, se precisará la concurrencia de los requisitos del art. 763.1 LEC para poder mantener el internamiento, empezando simultáneamente a correr el cómputo de las 24 horas para comunicarlo al órgano judicial». 
internamiento por el facultativo (STC 141/2012, FJ núm. 4.a) ${ }^{75}$; y por tanto, que junto al trastorno psíquico en sí (e insistimos, la imposibilidad de que el sujeto pueda consentir legítimamente su internamiento), se den otros motivos que generen la urgencia del internamiento, de manera que éste se practique sin la autorización judicial previa, al no poderse esperar la misma. Al respecto, entendemos (nuevamente) que tales «razones de urgencia» no son, en general, estrictamente concernientes al trastorno mental y su terapia ${ }^{76}$, sino respecto al riesgo que sobre quien padece el trastorno, o sobre tercero, quepa darse (riesgo sobre la vida o la integridad, en especial). Y consecuentemente, conforme se ha adelantado, que en este caso el internamiento ostente una finalidad fundamente protectora y/o aseguradora (ya de inocuización, o meramente asistencial), para evitar la materialización de dicho riesgo; de ahí su urgencia, justificando su adopción sin resolución (autorización) judicial previa.

En tal sentido, la comunicación del responsable del centro en que se haya producido el internamiento, dando cuenta al juez de dicho internamiento, deberá precisamente indicar no sólo el trastorno mental y la falta de actitud del internado para consentirlo, sino también, y especialmente (consideramos), las concretas razones que han concurrido para que se practicara el internamiento sin poderse esperar a la autorización judicial previa ${ }^{77}$; y ello, a efectos de que la ulterior resolución judicial, autorizando/ratificando el internamiento en su caso, pueda efectivamente constatar y controlar (diferidamente) tal razón/necesidad de urgencia, como parece entender el Tribunal Constitucional en su Sentencia 141/2012 (FJ núm. 5.d) ${ }^{78}$,

75 Asimismo, la STC 141/2012 señala como condición del internamiento urgente que el juez que haya de ratificarla valore «[l]a procedencia de la medida y su completa duración, deben satisfacer en cada caso concreto los requisitos de necesidad y proporcionalidad» (FJ núm. 4.b); no obstante, tal elemento no es solo parte del juicio a llevar a cabo un juez con ocasión de la ratificación de un internamiento involuntario urgente, sino también del mismo ordinario (tal como, de otra parte, así se ha señalado en el apartado anterior).

76 Decimos «en general», por cuanto que no cabe desdeñar supuestos en los que el internamiento, desde una perspectiva esencialmente terapéutica, resulte urgente en relación al trastorno metal que se padezca.

77 Además, y a nuestro parecer, sería oportuno indicar también cómo y dónde se desarrolla el internamiento.

78 «Control posterior sobre el centro: desde que tiene lugar la comunicación antedicha ha de considerarse que la persona pasa a efectos legales a disposición del órgano judicial, sin que ello exija su traslado a presencia física del juez, como hemos tenido ocasión de precisar en el ámbito de las detenciones judiciales (SSTC 21/1997, de 10 de febrero, FJ 4; 180/2011, de 21 de noviembre, FJ 5). Traslado que además tratándose de internamiento psiquiátrico contradiría la necesidad misma de la medida, de allí que lo normal es que el examen judicial directo del afectado se realice 
sin perjuicio de volver a ello en el siguiente apartado; y es que, de lo contrario, la función de autorización/control/ratificación judicial quedaría desnaturalizada y sin razón de $\operatorname{ser}^{79}$.

\section{IV.C Garantias en el internamiento involuntario y urgente, y de su ulterior control judicial}

De acuerdo al referido artículo 763.1 de la Ley de Enjuiciamiento civil, y al artículo 17.2 de la Constitución (así como al marco internacional-normativo anteriormente comentado), la primera garantía establecida en relación a un internamiento involuntario y urgente de una persona con trastornos psíquicos es el deber, por parte del director del centro en que se encuentra dicha persona internada, de comunicar al juez competente (el «del lugar en que radique el centro donde se haya producido el internamiento») tal internamiento en el plazo de 24 horas (según lo comentado supra). Sin embargo el Tribunal Constitucional, en su Sentencia 141/2012, señala otras dos garantías más en el momento del internamiento facultativo, no recogidas expresamente en el artículo 763 de la Ley de Enjuiciamiento Civil: la «[e]xistencia de un informe médico que acredite

en el propio establecimiento hospitalario. En todo caso, el director de este último sigue siendo responsable de la vida e integridad física y psíquica del interno mientras no acuerde el alta, bien por orden judicial o porque a criterio de los facultativos encargados se aprecie que han desaparecido o mitigado suficientemente las causas que motivaban el internamiento; incluso cuando tal ratificación judicial ya se hubiere producido».

79 «[...] el material de convicción del que el Juzgado dispuso para resolver, esto es, el informe de un folio del hospital universitario remitido el 3 de mayo de 2007, el acta de examen judicial personal del recurrente y el informe del médico forense, no permiten llegar al diagnóstico que describe el Auto en su Fundamento Segundo. Ninguno de esos informes ni tampoco el acta hablan de anulación de capacidades, ni cognitivas ni volitivas, del recurrente; limitándose los dos primeros (periciales) a referir un estado de trastorno bipolar de éste, y el acta judicial el resultado de su conversación con el Sr. Magistrado-Juez, sin ningún altibajo o anomalía en la conducta del interno referida en el Acta y menos aún la constatación de un estado de enajenación fundante de la necesidad de mantenerle interno. Que tanto el informe del hospital como también el del médico forense, recomendaran en un texto pre-impreso que continuara el internamiento, sin una concreta argumentación acerca de la necesidad y proporcionalidad de la medida, esto es, sin explicar por qué no hubiera bastado con un tratamiento ambulatorio para tratar el referido trastorno, como al parecer ya venía sucediendo con el recurrente, hace indebida su asunción acrítica por el Juzgado, quien ante ese vacío debió solicitar como mínimo aclaraciones o ampliación de su informe al médico forense, fuese para dar por ciertas aquellas notas de necesidad y proporcionalidad, fuese para no ratificar la medida caso de no obtener una opinión científica convincente» (nuevamente, STC 141/2012, FJ núm. 6.c). 
el trastorno psíquico justificante del internamiento inmediato» (FJ núm. 5.a) ${ }^{80}$; e «[i]nformación al afectado o su representante acerca del internamiento y sus causas», ya en este momento (FJ núm. 5.b) ${ }^{81}$.

Como segunda garantía legal, nuevamente (art. 763.1 LEC), está el que el juez deba resolver sobre la ratificación de la medida «en el plazo máximo de setenta y dos horas desde que el internamiento llegue» a su conocimiento ${ }^{82}$. Al respecto de este segundo plazo, el Tribunal Constitucional, otra vez en la referida Sentencia 141/2012, se muestra altamente contundente, al entender que en tal plazo el juez debe practicar las pruebas y ratificar «el internamiento o, en caso contrario, ordene su cesación» (FJ núm. 6.c). Y ello, además, considerando dicho plazo como «improrrogable», de manera que «no puede mantenerse el confinamiento de la persona si a su expiración no se ha ratificado la medida, ni cabe aducir dificultades logísticas o excesiva carga de trabajo del órgano judicial para justificar su demora, ni puede considerarse convalidado el incumplimiento porque más tarde se dicte el auto y éste resulte confirmatorio»; es más, pues «[v]encido el plazo no desaparece la facultad del juez para ordenar el internamiento, pero si éste se adopta deberá serlo estando el afectado en libertad, sin perjuicio de que tras esa ratificación deba ejecutarse la orden judicial con todos sus efectos» (FJ núm. 6.c, nuevamente) ${ }^{83}$. Por tanto, y siempre según el Tribunal Constitucional, «la superación del plazo de las 72 horas conllevará la vulneración del derecho fundamental del art. 17.1 CE» (FJ núm. 6.c, todavía).

Ciertamente, la anterior consideración del Tribunal resulta un tanto problemática, por cuanto que en dicho plazo se ha de enmarcar, a su vez, toda una serie de garantías procedimentales que el propio Constitucional señala, nuevamente en su Sentencia 141/2012, a fin de revisar «la procedencia del internamiento cuando se adoptó por el responsable sanitario», además «del estado mental del interno a la fecha en que tienen lugar las pruebas judiciales sobre

80 «[...] si bien el responsable del centro médico está facultado para tomar ab initio la decisión de internar a la persona, es evidente que esto se condiciona al hecho de que consten acreditadas en ese momento y tras su reconocimiento, la necesidad y proporcionalidad de la medida, de la que ha de informarse al interesado hasta dónde le sea comprensible, debiendo quedar plasmado por escrito el juicio médico para su posterior control por la autoridad judicial».

81 «[...] resulta evidente que nadie puede ser privado de libertad sin conocer los motivos que lo determinan, como proclama el art. 17.2 CE para la detención».

82 Plazo que, según la STC 141/2012, encuentra su base constitucional no en el art. 17.2 CE, sino en el 17.1 (FJ núm. 6.c, ab initio).

83 Sigue diciendo el Tribunal: «Otra interpretación llevaría a vaciar de contenido el límite previsto, confundiría lo que es una dilación procesal indebida con la lesión injustificada del derecho a la libertad e introduciría un abanico indefinido de flexibilidad, a todas luces peligroso e inconveniente». 
su persona» (FJ núm. 6) ${ }^{84}$. Así, y primeramente, «[e]l Juez ha de informar al interno o a su representante acerca de su situación material y procesal, lo que implica a su vez el derecho del afectado (o su representante en su nombre) a ser oído personalmente dentro del procedimiento»; y también el juez, de acuerdo al artículo 763.3 de la Ley de Enjuiciamiento Civil, deberá informar al privado de libertad «de su derecho a contar con abogado y procurador en este trámite y de su derecho a la práctica de pruebas» (FJ núm. 6.a $)^{85}$. Segundo, y en el plano probatorio, el juez ha «de efectuar el examen directo del interno en el centro», y «proveerá a la práctica del reconocimiento pericial por un médico designado por él» (FJ núm. 6.b). Y tercero, la motivación que ha de desarrollar el juez en su resolución, dado que reforzada al suponer la ratificación de la privación de libertad de una persona (FJ núm. 7.c), de modo que efectivamente el juez controle el internamiento llevado a cabo facultativamente (según se ha indicado más arriba $)^{86}$, junto con, claro está, la necesidad de su mantenimiento.

Difícilmente cabe, sin embargo, que en un plazo máximo de 72 horas un juez pueda resolver oportunamente sobre la ratificación de un internamiento involuntario y urgente en caso de oposición expresa del internado, y la solicitud

84 Sigue diciendo el Tribunal: «primero porque el juez, que es quien garantiza la tutela judicial efectiva (art. 24.1 CE), independiente (art. 117.1 CE) e imparcial (art. 24.2 CE) de los derechos del interno, debe determinar si la medida estuvo justificada en su origen, pues lo contrario llevaría a convertir la fase extrajudicial previa en un limbo sin derechos para el afectado. Pero segundo, porque si aparecen dudas fundadas acerca de la no necesidad de la medida en aquel primer instante $y$, sin embargo, sí parece justificarse a posteriori con el resultado de las pruebas judiciales, deberá dilucidar el tribunal si ello se debe a la implementación —o no- de un tratamiento inadecuado para el paciente, lo que dejando al margen otras consecuencias legales, podría ser justo motivo para no ratificarla».

85 «[... faltando la información sobre el derecho a la defensa jurídica y a la prueba, estos sencillamente no pudieron ser ejercitados. En este concreto ámbito, en el que la persona interna se halla prácticamente indefensa mientras está encerrada, la ley y la jurisprudencia de derechos humanos impone que el órgano judicial tome la iniciativa en la información, no presuponer su conocimiento por el afectado [...]» (FJ núm. 7.b).

86 Dice así el Tribunal expresamente en relación al caso a resolver en su STC 141/2012 (es por su trascendencia, que volvamos a copiar este párrafo en nota): «Que tanto el informe del hospital como también el del médico forense, recomendaran en un texto pre-impreso que continuara el internamiento, sin una concreta argumentación acerca de la necesidad y proporcionalidad de la medida, esto es, sin explicar por qué no hubiera bastado con un tratamiento ambulatorio para tratar el referido trastorno, como al parecer ya venía sucediendo con el recurrente, hace indebida su asunción acrítica por el Juzgado, quien ante ese vacío debió solicitar como mínimo aclaraciones o ampliación de su informe al médico forense, fuese para dar por ciertas aquellas notas de necesidad y proporcionalidad, fuese para no ratificar la medida caso de no obtener una opinión científica convincente. No habiéndolo hecho así, no cabe considerar, ni razonable ni dotada de la debida motivación reforzada, su decisión» (FJ núm. 7.c). 
por éste (y ulterior realización) de actividad probatoria (además del dictamen de un especialista, y la intervención del Ministerio Fiscal): ¿cómo articularse procedimental y adecuadamente todas esas exigencias en el plazo máximo de 72 horas? ${ }^{87}$ Y ello, además, bajo el expreso apercibimiento por parte del Constitucional de la puesta en libertad del internado en caso de extralimitación de dicho plazo por el juez, sin perjuicio de que una vez resuelva éste (ratificando el internamiento) se vuelva a proceder al internamiento; si como hemos adelantado, el internamiento urgente se fundamenta, esencialmente, en razones o motivos atinentes al riesgo que para quien tiene un trastorno psíquico, o para tercero, quepa darse, ¿cómo puede ponerse a tal persona en libertad, abriendo así la posibilidad de que se materialice dicho riesgo?

La respuesta a ambas interrogantes se ha de buscar, entendemos, a partir de una adecuada ponderación del caso en cuestión, con el referido plazo máximo de 72 horas para que resuelva el juez; plazo, además, en el que previamente se habrán de practicar, entendemos, las diligencias mínimas (legales, de oficio o instancia del interno) que puedan garantizar un adecuado y cautelar control judicial del internamiento efectivamente practicado ${ }^{88}$. Y así, y dado que siempre cabe la reconsideración de tal resolución por el juez (entendemos, en tanto que restrictiva de un derecho), como su recurso en apelación (art. 763.3, in fine, LEC), que una concepción maximalista de las garantías del interno quepan trasladarse desde el momento de la inicial ratificación judicial del internamiento urgente en 72 horas (desde la comunicación de dicho internamiento), a un ulterior momento, llegando a la apelación, por cuanto que entonces no habría el constreñimiento de las 72 horas ${ }^{89}$.

Tal vez el origen de esta concepción maximalista del Tribunal Constitucional, en cuanto a las garantías que han de rodear la ratificación de un internamiento involuntario y urgente por trastorno psíquico (en la que, no se olvide, se atribuyen unas facultades procesales a una persona, el internado,

87 «Se trata de un procedimiento que habrá de sustanciarse con arreglo a las normas de la jurisdicción voluntaria. El proceso tipo del Art. 753 (juicio verbal con contestación escrita a la demanda) es incompatible con la celeridad con que normalmente se debe desarrollar y resolver el proceso, al igual que lo es en general la estructuración de un proceso contencioso en el que se haya de designar al enfermo un defensor judicial»; Juan CALPARSORO DAMIÁN, «La actuación del Ministerio Fiscal en defensa de las personas declaradas incapaces», en AA.VV. Jornadas sobre Protección Jurídica en la Incapacidad... cit., p. 53. Asimismo, de interés, Juan Antonio ARIAS GARCÍA, «Internamiento no voluntario por razón de trastorno psíquico», Boletín de Información del Ministerio de Justicia, núm. 2016, 2006, pp. 21 a 23, y 34.

88 Pero siempre, mínimas-mínimas necesarias.

89 Sin perjuicio de la preferencia con que ha de resolverse tal recurso, conforme al art. 753.3 LEC, y al hallarse derechos fundamentales afectados. 
que, en principio, se le achaca no sólo un trastorno metal, sino además una carencia volitiva y cognitiva para consentir por sí mismo su internamiento), se encuentre en una confusión en relación al fundamento del internamiento y de las garantías que han de rodearlo. Así, parecería haberse trasladado las garantías procesales generalmente definidas en torno al detenido (propias del Estado de Derecho), basadas en última instancia en la presunción de inocencia en el ámbito penal, al internado por trastornos mentales y en base, ahora, a una hipotética presunción de salud mental ${ }^{90}$; y ello, además, cuando en casos de urgencia se trata, en el que el internamiento busca evitar, con carácter general (según hemos adelantado), la materialización de un riesgo grave para la propia persona del interno, o de tercero (conforme a un deber de actuación de los poderes públicos propio del Estado Social). Cierto que el internamiento de una persona con trastorno mental, en tanto que limitación de la libertad personal, ha de realizarse con las garantías adecuadas para evitar una restricción ilegítima de su libertad (art. 17.1 CE); pero ello, sin perjuicio de basarse en presupuestos distintos a las restricciones de la libertad personal de carácter penal o sancionador (es el caso, por ejemplo, del internamiento de extranjeros a fin de su expulsión, conforme art. 62 LO 4/2000, de 11 de enero), como también sucede con relación a la incomunicación forzosa y urgente de enfermos infectocontagiosos (arts. 2 y 3 LO 3/1986, de 14 de abril, 8.6 L 29/1998, de 13 de julio, y 9.2.a L 41/2002; además, art. 5.1.e Convenio para la Protección de los Derechos Humanos y de las Libertades Fundamentales). En estos supuestos la paradoja se da al procurar con el internamiento involuntario y urgente por trastorno mental (al igual que con la incomunicación forzosa y urgente de enfermos infecto-contagiosos) una finalidad que trasciende el control físico del detenido y la mera legalidad (penal y administrativa), a fin de evitar un riesgo cierto y grave que afecte tanto al interno, como a terceros, y respecto sobre el cual existe un deber de los poderes públicos de actuar y garantizar ${ }^{91}$; y así, la inadecuación de la mera traslación de unas garantías plateadas frente al ius puniendi y sancionador del Estado en relación a la libertad personal, a otros supuestos, como es el caso del internamiento forzoso e involuntario por trastorno metal, en los que los poderes públicos están precisamente obligados

90 Una presunción que busca evitar, a su vez, una inadecuada similitud entre la estigmatización penal y la mental, pero en la que finalmente parecería recaer.

91 De un fundamento social hablamos ya en nuestro citado trabajo «Restricciones en orden a la protección de la salud...», cit., pp. 133-35. 
a velar por la integridad y la salud de las personas ante un riesgo grave, cierto y urgente (arts. 15 y $49 \mathrm{CE})^{92}$.

Por otra parte, el Tribunal parece extender al interno, y en relación a la ratificación judicial del internamiento involuntario y urgente, la tutela judicial efectiva (art. 24.1 CE), cuando afirma que corresponde al juez garantizar la misma (STC 141/2012, FJ núm. 6). Sin embargo, si (como venimos aduciendo) la ratificación judicial (como autorización diferida) se aproxima más a una intervención no jurisdiccional en garantía de derechos (pues el juez ha de actuar incluso cuando el interno apoya la medida, pero carece de capacidad volitiva y cognitiva suficiente para consentir) ${ }^{93}$, la extensión de la tutela judicial resulta mediatizada por el tipo de función judicial a desarrollar y los fines perseguidos por ésta; y de este modo, que la extensión de la tutela judicial en el ejercicio de funciones no jurisdiccionales en garantía de derechos no sea del todo equiparable al caso en el que el juez ejerce auténtica función jurisdiccional ${ }^{94}$. Otra cosa es, obviamente, que en el procedimiento de ratificación la persona internada se oponga expresamente a su internamiento, y solicite (directamente ella, o por medio de abogado) la realización de pruebas dirigidas a refutar la necesidad de su internamiento; naturalmente, en este caso, la tutela judicial (jurisdiccional) toma mayor presencia, sin perjuicio

92 Claro que esto último no puede suponer un poder ilimitado y abstracto a favor de los poderes públicos frente a las personas que supuestamente pretende proteger (insistimos), y de este modo, que tales poderes públicos han de quedar asimismo limitados en su actuación en garantía precisamente de las personas (arts. 15 y 17 CE, así como la normativa internacional anteriormente señalada). Mas ello, entendemos, en un marco de garantías que, aunque suficientes y efectivas, respondan adecuadamente al conflicto de intereses y bienes constitucionales que en tales casos concurren, y que es diverso al que se da con ocasión de una detención de tipo penal o sancionadora.

93 Y ello, en razón a como la base constitucional de las funciones judiciales relativas a la garantía de los derechos fundamentales reposa en dos ejes: una, la referida tutela judicial, y desarrollándose con ocasión del ejercicio de la función jurisdiccional (art. 24.1 y 117.3 CE); y otra, la garantía ante limitaciones de derechos, de acuerdo a específicas referencias constitucionales (así, 17.2 y 18.2 y 3 CE, y en conexión con el marco internacional anteriormente presentado), además de la genérica previsión de atribución de funciones no jurisdiccionales en garantía de derechos (art. 117.4 CE). Al respecto, Juan Francisco SÁNCHEZ BARRILAO, «La garantía de los derechos fundamentales, y el juez como garante ordinario de los mismos», en AA.VV. XXV Aniversario de la Constitución Española: propuestas de reformas, María Luisa Balaguer Callejón (coord.), Diputación de Málaga, Málaga, 2004, pp. 575 y ss.

94 Nuevamente Juan Francisco SÁNCHEZ BARRILAO, pero ahora (otra vez), Las funciones no jurisdiccionales de los jueces en garantía de derechos... cit., pp. 185 y ss. 
de las dificultades procedimentales que supone (según se ha comentado más arriba) el que ello haya de resolverse por el juez en el plazo de 72 horas desde su comunicación ${ }^{95}$.

95 A esto, además, parecería sumarse cierta confusión que advertimos respecto a diversas concepciones que concurren sobre la intervención del juez con ocasión de internamientos involuntarios y urgentes en caso de trastorno mental; nos referimos a la concurrencia de dos concepciones diversas en Derecho comparado en relación a la intervención judicial respecto a la garantía de los derechos ante la intervención de los poderes públicos: de un lado, y desde el Derecho anglo-americano, el derecho de audiencia y al debido proceso, y de otro, la tutela judicial efectiva, más propio del Derecho continental-europeo (y bajo la influencia del Derecho francés). Y ello, además, desde una mayor aproximación de los instrumentos internacionales relativos a derechos humanos a la primera concepción, que a la segunda, sin perjuicio de las recíprocas influencias que al tiempo cabe advertir al respecto. Pero veámoslo más despacio: En la concepción del derecho de audiencia, cualquier intervención del poder público que afecte a los derechos de las personas (en particular los fundamentales), requieren de previa audiencia, o al menos casi paralela audiencia (de aquí, el origen del habeas corpus inglés), ante el juez a fin de que autorice/controle dicha intervención; y esto, fundamentalmente, desde la relativa equiparación desde la que se parte entre ciudadanos y poderes públicos. En cambio, y desde el Derecho público francés (y su proyección cultural y jurídica), las prerrogativas de la Administración han permitido una mayor capacidad de actuación de los poderes públicos frente a los ciudadanos, sin perjuicio de que éstos puedan posteriormente solicitar su control jurídico en relación a los derechos e intereses legítimos que entran en conflicto con tal actuación pública; y control que será no sólo jurídico, sino jurisdiccional y judicial cuando éste recae, como sucede en España, en el Poder Judicial (así, art. 24.1, 106.1 y 117.1 y 3 CE). Ambas concepciones, eso sí, no se presentan puras, y las referidas influencias recíprocas, junto al peso de la historia en las instituciones jurídicas, explican figuras jurídicas que asumen elementos de las otras concepciones, como así sucede expresamente a nivel constitucional en España a la vista del artículo 117.4 de la Constitución (más otros preceptos con previsión expresa de intervención judicial, como son los arts. 17.2, o 18.2 y $3 \mathrm{CE}$ ); pero ello, con todo, sin perjuicio de reconocer como los modelos son susceptibles de ser reconocidos (a pesar de ulteriores matizaciones). En tal sentido, el modelo español reposa esencialmente en la tutela judicial, la cual garantiza fundamentalmente una última intervención judicial en garantía de un derecho o interés legítimo en conflicto declarado, sin perjuicio de que, en garantía de determinados derechos, el ordenamiento jurídico (incluida la CE) provea la intervención previa o coetánea judicial de los mismos en atención al interés que sobre éstos recae a fin de evitar, y no sólo resolver, su lesión; y esto último, sin que a veces llegue a intervenir directamente la persona afectada, por cuanto que la actuación del juez está dirigida a garantizar sus derechos y libertades frente a una actuación pública sobre el mismo (sin perjuicio, eso sí, de que al tiempo pueda promover la tutela judicial efectiva de sus derechos, por considerarlos lesionados o perturbados por los poderes públicos). La anterior disquisición cobra cuerpo, precisamente, con ocasión de la comentada STC 141/2012, cuando, y al amparo del ordenamiento internacional, establece un ceñido régimen constitucional (ceñido no por estrecho o reducido, sino por encorsetado, apretado y rígido) en relación a las garantías procesales que han de darse en la intervención judicial en ratificación de un internamiento involuntario y urgente por trastorno mental (según se ha visto). 


\section{EL MINISTERIO FISCAL Y EL INTERNAMIENTO INVOLUNTARIO Y URGENTE POR TRASTORNO MENTAL}

Si con carácter general se ha de admitir el progreso que supone la Sentencia del Tribunal Constitucional 141/2012 en el entendimiento constitucional del internamiento involuntario y urgente de personas que padecen trastornos mentales (sin perjuicio de las consideraciones antes planteadas) ${ }^{96}$, hay no obstante un aspecto de la Sentencia que, y al respecto del procedimiento de la ratificación judicial de la medida, no compartimos; nos referimos al mitigado rol que de la intervención del Ministerio Fiscal plantea el Constitucional en relación al control de un internamiento involuntario y urgente por trastorno mental, al entender que la defensa del internado no queda suficientemente cubierta con la «presencia del Ministerio Fiscal, el cual actúa en defensa de la legalidad y no como defensor judicial del interno, quien ha de tener por tanto siempre su propia voz y defensa dentro del procedimiento, ya que en este momento procesal no está declarado incapaz» (FJ núm. 7.b). Cierto es que una persona con un trastorno mental que requiera de internamiento no tiene porqué estar judicialmente declarado incapaz, pero igualmente es cierto que la Ley de Enjuiciamiento Civil considera el internamiento involuntario por trastorno psíquico como un procedimiento especial relativo a la capacidad de las personas (Cap. II, Tít. I, Lib. IV LEC), con lo que, además de prever la intervención del Ministerio Fiscal expresamente en su artículo 763.3 (ha de ser escuchado), cabría deducir su participación con carácter general al amparo del artículo 749 de la misma (y expresa, eso sí, para el caso en que la persona afectada sea un menor, o esté efectivamente declarado incapaz), y de manera particular, incluso, a la vista de su 758 (siempre y cuando no sea el Ministerio Fiscal el promotor de la actuación) $)^{97}$; y es que, no se olvide, se está ante un internamiento que se considera involuntario, dadas las carencias cognitivas y volitivas de una persona para poder consentir legítimamente su internamiento, y de ahí precisamente la especial situación de debilidad e indefensión en que esta persona se puede encontrar (sobre lo que insistimos, y

96 A esta altura del trabajo, bien puede haber advertido el lector que buena parte del mismo gira en torno a matices; matices que, más allá de un supuesto rigor científico, buscan en esta ocasión perfilar críticamente una doctrina, la de la STC 141/2012, que ostenta la pretensión de enmarcar con carácter general y abstracto el régimen constitucional de los internamientos involuntarios y urgentes de quienes padecen trastornos mentales (como se adelantó al comienzo de estas páginas). De ahí precisamente la importancia de esta STC, y la necesidad de reflexionar sobre su alcance.

${ }_{97}$ Cfr. Concepción ESPEJEL JORQUERA, «El internamiento no voluntario por razón de trastorno psíquico...», cit., pp. 55 y 56. 
la referida STC 141/2012 no parece detenerse oportunamente, cuando ello es presupuesto precisamente de la ratificación —o autorización diferida — judicial del internamiento de una persona con trastorno psíquico).

Por tanto, aunque el procedimiento judicial autorizando el internamiento, ordinario o urgente, de una persona con trastorno mental no puede considerarse como de incapacitación, ni el internado ha de entenderse como incapacitado judicialmente (sin perjuicio de que pueda estarlo), sí que cabe considerarlo como una persona que, al momento de practicarse el internamiento adolece (temporal, o de manera permanente) de la actitud necesaria para consentir dicho internamiento, y por tanto cabría, en cierto modo, equipararse, a los solos efectos de su adecuada garantía, como incapaz ${ }^{98}$. Claro que la intervención del Ministerio Fiscal no puede sustituir la voluntad de la persona a internar (o internada), ni negar la posibilidad de que ésta encargue su defensa a un abogado, pero sí que es cierto que precisamente la actitud cognitiva y volitiva limitada en que ella se encuentre puede hacer del todo punto ineficaz (y dejar sin sentido) tales garantía procesales ${ }^{99}$.

Naturalmente dicha intervención del Ministerio Fiscal en este procedimiento requiere de una actuación que sobrepasa su simple audiencia ante el juez, y consecuentemente que deba asumir una participación más directa y personal con relación a la persona a internar (o internada), como respecto a todo el desarrollo del procedimiento judicial; y esto (y superando así la estricta y limitada previsión que a tales efectos plantea el art. 763.3 LEC), según la consideración del Ministerio Fiscal como garante institucional que de los derechos fundamentales cabe deducir del artículo 124.1 de la Constitución y, en su desarrollo, de su Estatuto Orgánico (art. 3.3 y 3.7 L 50/1981, de 30 de diciembre) ${ }^{100}$.

\section{CONSIDERACIONES FINALES}

La vigencia provisional del artículo 763.1 de la Ley de Enjuiciamiento Civil, a la luz de la referida Sentencia del Tribunal Constitucional $132 / 2010$, se ha vuelto a poner en evidencia en la también comentada

98 No obstante, en contra de tal parecer, Juan CALPARSORO DAMIÁN, «La actuación del Ministerio Fiscal en defensa de las personas declaradas incapaces...», cit., p. 53.

99 Debiendo entonces el Ministerio Fiscal asumir de oficio tal función en garantía de los derechos y libertades de la persona a internar o internada, y llevando a cabo, de este modo, un rol más allá de la mera defensa de la legalidad.

100 Entre otros: Enrique ÁLVAREZ CONDE, «El sistema constitucional español de derechos fundamentales», Corts: Anuario de Derecho Parlamentario, núm. 15, 2004, p. 143; o Yolanda GÓMEZ SÁNCHEZ, Derecho Constitucional Europeo: derechos y libertades, Sanz y Torres, 2005, Madrid, pp. 458 y ss. 
Sentencia 141/2012 (FJ núm. 3, in fine), en la que nuevamente se insta al legislador orgánico a dar adecuada y pronta cobertura legal-orgánica a las concretas normas que hayan de autorizar el internamiento involuntario y urgente por trastorno mental ${ }^{101}$. A tales efectos (entendemos), sería oportuno volver a introducir en el Código Civil los supuestos en los que cabe tal internamiento (mediante ley orgánica, eso sí), mientras que en la Ley de Enjuiciamiento Civil (art. 763) se mantiene su desarrollo procedimental; y también, especificando expresamente si dicho internamiento cubre, o no, el supuesto de personas dependientes y ancianos (art. 4.2.h Ley 39/2006), a tenor de las dudas actualmente abiertas.

Pero la referida y necesaria reforma, junto con la doctrina recientemente vertida por el Tribunal Constitucional en su Sentencia 141/2012, sería asimismo (según nuestro parecer) ocasión para volver a reformar el vigente artículo 763 de la Ley de Enjuiciamiento Civil, a fin de adecuarlo al marco constitucional deducido por el alto Tribunal al respecto del internamiento involuntario y urgente de una persona con trastorno mental. Y ello: de un lado, recogiendo los requisitos deducidos por el Constitucional y que no se encuentran expresamente en el artículo 763; y de otro, resolviendo normativamente las dificultades procedimentales que surgen, y hemos advertido, con ocasión de cómo se ha de llevar a cabo dichos internamientos según la Sentencia 141/2012.

Así, y en cuanto a lo primero, sería adecuado que una oportuna reforma del artículo 763 de la Ley de Enjuiciamiento Civil recogiera, en relación al momento del internamiento facultativo involuntario y urgente de una persona con trastorno mental, que el facultativo responsable de dicho internamiento informe «al afectado o su representante acerca del internamiento y sus causas» (STC 141/2012, FJ núm. 5.b, además de arts. 4 y ss. L 41/2002); y que el internamiento urgente quede acreditado (tras el reconocimiento de la persona por el facultativo) en un informe médico en el que conste asimismo y expresamente «la necesidad y proporcionalidad de la medida» (de lo que ha de informarse, a su vez, «al interesado hasta dónde le sea comprensible»), a fin todo ello de permitir

101 «[...] optamos por un pronunciamiento de inconstitucionalidad sin nulidad de las disposiciones, al no haberse cuestionado su contenido material y atendiendo al vacío no deseable que de otro modo se hubiera creado dentro del ordenamiento. Instamos entonces al legislador a que "a la mayor brevedad posible, proceda a regular la medida de internamiento no voluntario por razón de trastorno psíquico mediante ley orgánica" (STC 132/2010, FJ 3), sin que a día de hoy este requerimiento haya sido todavía atendido, por lo que procede reiterarlo». La cursiva es nuestra. 
su posterior control por autoridad judicial (STC 141/2012, FJ núm. 5.a) ${ }^{102}$. Por otra parte, y ya en la ulterior fase de control judicial, la ley debería requerir además, y de manera concreta, que el juez informe: «al interno o a su representante acerca de su situación material y procesal», y consiguientemente del derecho del afectado, o de su representante en su nombre, a ser oído personalmente por aquél; y también, del derecho del internado «a contar con abogado y procurador en este trámite y de su derecho a la práctica de pruebas» (STC 141/2012, FJ núm. 6.a). En el plano probatorio, el juez ha «de efectuar el examen directo del interno en el centro» de internamiento (STC 141/2012, FJ núm. 6.b), junto con aquellas otras pruebas propuestas por el internado (en su caso), y sean relevante al caso. Y en fase ya de decisión judicial, que la resolución del juez contenga una motivación reforzada que comprenda la «necesidad y proporcionalidad de la medida», de modo que efectivamente el juez controle el internamiento llevado a cabo facultativamente (STC 141/2012, FJ núm. 7.c).

Por otra parte, y en relación a las cuestiones abiertas por el Tribunal Constitucional en su Sentencia 141/2012 respecto al procedimiento de ratificación judicial del internamiento involuntario y urgente por trastorno mental (y según lo advertido con anterioridad), resultaría oportuno asimismo que una reforma del artículo 763 de la Ley de Enjuiciamiento Civil viniera a procurar una tramitación más adecuada del procedimiento de ratificación judicial, en particular ante el límite estricto que supone las 72 horas para el juez (FJ núm. 6.c) y la genérica referencia a su tramitación mediante el juicio verbal (art. 753 LEC). En tal sentido, siendo el límite temporal infranqueable por el juez, a la par que en tal plazo ha de integrarse todo un potencial de actuaciones judiciales que, como mínimo, incluye el examen y audiencia del internado, la audiencia al Ministerio Fiscal y de otros posibles interesados, el examen también del internado por un facultativo designado judicialmente (y la ulterior audiencia judicial a tal facultativo), la práctica de aquellas pruebas propuestas por el interno (en su caso), así como (claro está) el examen del informe médico realizado por el facultativo que originariamente acordó el internamiento y el nombramiento de abogado y procurador (incluso de oficio) para el supuesto en que sea solicitado por el

102 De este modo, la comunicación del responsable del centro en que se haya producido el internamiento, dando cuenta al juez para su ratificación, deberá contener tal informe médico (en el que conste el trastorno metal y la falta de actitud del internado para consentir el internamiento, claro está), sino también, entendemos, las concretas razones que han concurrido para que se practicara el internamiento sin poderse esperar a la autorización judicial previa, además de cómo y dónde se desarrolla el internamiento; y ello (conforme se viene indicando), a efectos de que la ulterior resolución judicial, autorizando/ratificando el internamiento en su caso, pueda efectivamente constatar y controlar (diferidamente) tal razón/necesidad de urgencia (de acuerdo a STC 141/2012, FJ núm. 5.d). 
interno ${ }^{103}$, se ha de procurar una tramitación judicial exprés que, sin perjuicio de garantizar las mínimas garantías referidas, permita al menos una resolución judicial cautelar en 72 horas (manteniendo, o no, el internamiento), mas sin perjuicio de un ulterior pronunciamiento del juez sobre la efectiva ratificación del internamiento, cuando la complejidad del asunto así lo requiera ${ }^{104}$.

Por último está también la cuestión de la intervención del Ministerio Fiscal más allá de la mera audiencia que señala la ley (art. 763.3 LEC), y en especial para casos en los que el interno no activa oportunamente las garantías anteriormente referidas; y ello, ante la situación de debilidad e indefensión en la que cabe encontrarse el interno en razón precisamente al trastorno mental que padece y la falta de capacidad volitiva y cognitiva necesaria para consentir, o no, el internamiento. ¿No debería darse legalmente una mayor intervención al Ministerio Fiscal al respecto, y en particular para el caso en que el interno no solicite la asistencia de un abogado?.

Como se ve, son varias las cuestiones que quedan todavía abiertas tras la Sentencia 141/2012 del Tribunal Constitucional en relación al régimen constitucional del internamiento involuntario y urgente por trastorno mental, y a las que debería darse oportuna y adecuada respuesta y desarrollo legal.

Title:

CONSTITUCIONAL FRAMEWORK ON INVOLUNTARY AND URGENT CONFINEMENT DUE TO MENTAL DISORDER

\section{Index:}

I. Introduction: Spanish Constitutional Courts Judgemnets 141/2012, 131/2010 and 132/2010. II. Confinement Due To Mental Disorder, Legal Framework: II.A Constitutional Framework; II.B International Legal Framework; II.C National Legal Framework. III. Nature of Confinement Due to Mental Disorder: III.A Nature of Confinement: Among Terapeutic and Innoccuous and/or Care Mi-

103 Sin perjuicio, además, de la actualización de los protocolos de actuación que ya existen entre los distintos sujeto a intervenir en ocasión de internamientos involuntarios y urgentes de personas con trastornos mentales, a fin de conseguir no sólo una mayor cooperación y coordinación, sino también una mayor rapidez; sobre tales protocolos y su importancia, vid. Concepción ESPEJEL JORQUERA, «El internamiento no voluntario por razón de trastorno psíquico... cit., pp. 58 y ss.

104 Con todo, quedaría abierto el supuesto de no resolución judicial en dicho plazo, y sobre el interno, a consideración del centro en el que éste se encuentra, recae un riesgo cierto para su integridad y vida, o de tercero; ¿debe el centro ponerlo en libertad, conforme se desprende de la STC 14172012?, o bien ¿cabe la posibilidad de mantener el internamiento ante la situación de necesidad planteada?. Para tal caso, una garantía adicional siempre sería el habeas corpus (art. 17.4 CE). 
sures; III.B Nature of Judicial Intervention: Judicial Authorization and Warranty of Rights IV. Involuntary and Urgent Confinements Due to Mental Disorder: IV.A Prelude: Ordinary Involuntary Confinements Due Mental Disorder; IV.B Premises about Involuntary and Urgent Confinements Due to Mental Disorder; IV.C Procedural Guarantees, and Judicial Control on Involuntary and Urgent Confinements. V. Confinements Due to Mental Disorder and Public Prosecution. VI. Conclusions.

\title{
Resumen:
}

El presente trabajo aborda el régimen constitucional de los internamientos involuntarios y urgentes por trastorno mental como un supuesto de limitación de derechos fundamentales (especialmente, libertad personal); y, en particular, a la vista de la doctrina contenida en la Sentencia del Tribunal Constitucional 141/2012, dictada en resolución de un recurso de amparo al respecto. En tal sentido, se analiza el marco normativo de dichos internamientos (distinguiendo entre el estrictamente constitucional, el internacional y el meramente legal), su naturaleza (en relación al internamiento como tal, como respecto a la intervención judicial que ha de autorizarlo), sus concretas garantías (en especial, a la vista de la STC 141/2012), así como diversas cuestiones abiertas por la anterior Sentencia, no obstante, y que requieren de oportuna respuesta legal.

\section{Palabras clave:}

Internamiento involuntario y urgente por trastorno mental, libertad personal, consentimiento informado, autorización judicial.

\begin{abstract}
:
The following piece of paper deals with the constitutional rule of the involuntary and urgent confinements due to mental disorder as restricting fundamental rights (especially, personal liberty) according to the principles established in the judgement of the Spanish Constitutional Court 141/2012. Accordingly, the legal frameworkof a such confinements is analysed (making a distinction among constitutional, international and legal rules), its nature (ref. both confinements itself, as the role of judge who must authorize), its specific guarantees (in accordance with the judgement STC 141/2012), as well as a variety of issues requiring a timely legal response.
\end{abstract}

\section{Keywords:}

Involuntary and urgent confinement due to mental disorder, personal liberty, informed consent, judicial authorization. 
